\title{
Reduced follicular regulatory $T$ cells in spleen and pancreatic lymph nodes of patients with type 1 diabetes
}

\section{Short running title: Tfr cells in blood, spleen, and PLN in hu T1D}

Andrea Vecchione ${ }^{1,2}$, Tatiana Jofra ${ }^{1}$, Jolanda Gerosa ${ }^{1}$, Kimberly Shankwitz ${ }^{3}$, Roberta Di Fonte $^{1 \neq}$, Giuseppe Galvani ${ }^{1}$, Elio Ippolito ${ }^{1}$, Maria Pia Cicalese ${ }^{4,5,6}$, Andrew R. Schultz ${ }^{7}$, Howie R. Seay ${ }^{7}$, Mariagrazia Favellato ${ }^{1}$, Giulia Milardi ${ }^{1}$, Angela Stabilini ${ }^{1}$, Francesca Ragogna ${ }^{1}$, Pauline Grogan ${ }^{8,9}$, Eleonora Bianconi ${ }^{8,9}$, Andrea Laurenzi ${ }^{8}$, Amelia Caretto ${ }^{8}$, Rita Nano ${ }^{1}$, Raffaela Melzi ${ }^{1}$, Nichole Danzl ${ }^{2}$, Emanuele Bosi ${ }^{1,6,8,9}$, Lorenzo Piemonti ${ }^{1,6,8}$, Alessandro Aiuti $^{4,5,6}$, Todd Brusko ${ }^{7,10}$, Constantinos Petrovas $^{3}$, Manuela Battaglia ${ }^{1,9}$, and Georgia Fousteri $^{1 *}$

${ }^{1}$ Diabetes Research Institute (DRI), IRCCS San Raffaele Scientific Institute, Milan, Italy

${ }^{2}$ Columbia Center for Translational Immunology, Columbia University Medical Center, New York, NY, United States ${ }^{3}$ Tissue Analysis Core, Immunology Laboratory, Vaccine Research Center, National Institute of Allergy and Infectious Diseases, National Institutes of Health, Bethesda, MD 20892, USA

${ }^{4}$ San Raffaele Telethon Institute for Gene Therapy (HSR-TIGET), IRCCS San Raffaele Scientific Institute, Milan, Italy

${ }^{5}$ Pediatric Immunohematology and Bone Marrow Transplantation Unit, IRCCS San Raffaele Scientific Institute, Milan, Italy

${ }^{6}$ Vita-Salute San Raffaele University, Milan, Italy

${ }^{7}$ Department of Pathology, Immunology, and Laboratory Medicine, University of Florida Diabetes Institute, Gainesville, FL, United States

${ }^{8}$ Department of Internal Medicine, IRCCS San Raffaele Hospital, Milan, Italy

${ }^{9}$ TrialNet Clinical Center, IRCCS San Raffaele Hospital, Milan, Italy

${ }^{10}$ Department of Pediatrics, University of Florida College of Medicine, Gainesville, FL, United States

₹Current address: Istituto Tumori IRCCS "Giovanni Paolo II", Bari, Italy

Corresponding Author: Dr. Georgia Fousteri, Diabetes Research Institute (DRI), IRCCS San Raffaele Scientific Institute, Milan, Italy, E-mail address: fousteri.georgia@hsr.it, phone: +39022643-3184, Fax: +39-022643-7759

\section{Word count:}


N. Figures: 4; N. Tables: 7 


\title{
Summary
}

By analyzing rare spleen and pancreatic lymph nodes samples from T1D donors, we found follicular regulatory $\mathrm{T}$ cells to be significantly reduced in frequency and number suggesting they contribute to the development of islet-specific autoantibodies and the loss of immune tolerance in Type 1 diabetes.

\begin{abstract}
In the attempt to understand the origin of autoantibody ( $\mathrm{AAb}$ ) production in patients with and at-risk for T1D, multiple studies have analyzed and reported alterations in follicular helper T cells (Tfh) in presymptomatic AAb-positive subjects and patients with T1D. Yet, it is still not clear whether the regulatory counterpart of $\mathrm{Tfh}$ cells, represented by follicular regulatory $\mathrm{T}$ cells (Tfr), is similarly altered. To address this question, we performed analyses in peripheral blood, spleen and pancreatic lymph nodes (PLN) of organ donor subjects with T1D. Blood analyses were also performed in living AAb-negative and -positive subjects. While negligible differences in the frequency and phenotype of blood Tfr cells were observed between T1D, AAb-negative and AAb-positive adult subjects, the frequency of Tfr cells was significantly reduced in spleen and PLN of T1D as compared to non-diabetic controls. Furthermore, adoptive transfer of Tfr cells delayed disease development in a mouse model of T1D, a finding that could indicate that Tfr cells play an important role in peripheral tolerance and regulation of autoreactive Tfh cells. Together, our findings provide evidence of Tfr cell alterations within disease-relevant tissues in patients with T1D suggesting a role for Tfr cells in defective humoral tolerance and disease pathogenesis.
\end{abstract}

\section{Abbreviations}

T1D Type 1 diabetes

AAb Autoantibody

HC Healthy control

Treg T regulatory

Tfh T follicular helper

Tfr T follicular regulatory

GC Germinal center

CXCR5 Chemokine (C-X-C motif) receptor type 5

PD-1 Programmed cell death protein 1

ICOS Inducible T cell co-stimulator 
CXCL13 Chemokine (C-X-C motif) ligand 13

PLN Pancreatic lymph node

SLO Secondary Lymphoid Organs

TCZ T cell zone

RT Room temperature

HLA Human leukocyte antigen

Ig Immunoglobulin

\section{Keywords}

Type 1 diabetes

Follicular helper T cells

Follicular regulatory T cells

Spleen

Pancreatic lymph nodes

Immune tolerance 


\section{Introduction}

Type 1 diabetes (T1D) is an autoimmune disease characterized by the destruction of pancreatic beta cells (1). Abnormalities in T-cell activation, function and differentiation drive development of autoimmunity in patients and mouse models of T1D (2). In humans, detection of multiple islet-specific autoantibodies (AAbs) and impaired a glucose tolerance divide progression to T1D into two progressive stages leading to insulin dependence (3). Asymptomatic individuals positive for two or more diabetes-related AAbs are classified as patients with stage $1 \mathrm{~T} 1 \mathrm{D}$, while those who have additionally developed impaired glucose tolerance are classified with stage 2 T1D.

$\mathrm{T}$ follicular helper (Tfh) cells are a subset of $\mathrm{CD}^{+} \mathrm{T}$ cells, highly specialized in promoting efficient antibody production from B cells in germinal centers (GCs) of the spleen and secondary lymphoid organs (SLOs) (4-7). Tfh cells are characterized by the expression of chemokine (C-X-C motif) receptor type 5 (CXCR5) (8,9), production of IL-21 (10) and high levels of activation markers inducible T cell co-stimulator (ICOS) and programmed cell death protein 1 (PD-1) (11,12). Higher Tfh cell activity is linked to production of AAbs in T1D $(13,14)$. T follicular regulatory (Tfr) cells also express CXCR5, PD-1 and ICOS, but are a subset of $\mathrm{FOXP}^{+} \mathrm{T}$ regulatory cells (Treg) that inhibit AAb production (15-17).

Tfh cells transiting in peripheral blood can be segregated into four functionally distinct populations based on expression of chemokine receptors, CXCR3 and CCR6 (17-19). Activated (PD-1 ${ }^{\text {hi ICOS }}{ }^{+}$) blood Tfh cells transiently expand following vaccination and infection, and were found increased in patients with T1D and other autoimmune diseases $(13,20-22)$. Blood Tfr cells also increase after vaccination or infection, and are elevated in the blood of patients with autoimmunity, but their role in progression to T1D is unknown (23-25). Recently, Fonseca et al., found an increased number of blood Tfr cells in patients with Sjogren's syndrome that lacked suppressive potential in vitro, and suggested that an that increased number of blood Tfr cells indicates ongoing humoral activity (26). The same group showed that GC and circulating Tfr cells arise independently via a bifurcated trajectory from $\mathrm{FOXP}^{+}$precursor Treg cells suggesting that blood Tfr cells are not good indicators of the SLO-residing Tfr cells (27).

The development of high-affinity class-switched islet-specific AAbs in GCs may be controlled by $\mathrm{Tfh}$ and $\mathrm{Tfr}$ cells $(14,28)$. In peripheral blood, Tfh cell-associated genes such as BCL6, IL21, CXCR5, PDCD1, CXCL13, ICOS were upregulated in memory CD4+ T cells from adults with long-standing T1D (22). Consistent with this observation, other studies have shown the frequency of circulating activated Tfh cells to be elevated in adult T1D patients $(29,30)$. 
Activated Tfh cells were also increased in the peripheral blood of children with stage 1 or stage 2 T1D, with the relative frequency of Tfh cells increasing in stage 2 T1D (13). The expansion of activated blood Tfh cells in patients with T1D may be due to migration of cells from SLO as a recent histological study showed a reduction in the number of GCs in the pancreatic lymph node (PLN) in T1D patients (31). Previously, we reported an elevated frequency of Tfr cells in peripheral blood of children with new-onset T1D as compared to healthy children (25). However, much still is unknown about the frequency, phenotype, and function of Tfr cells in T1D and, particularly, in the tissues where these cells function and reside.

We hypothesized that there would be an alteration of $\mathrm{Tfr}$ cell number and immunosuppressive function in SLO of patients with T1D leading to the generation of AAb. Given the limited number of studies assessing the contribution of Tfr in islet autoimmunity, we analyzed Tfh and Tfr cells in peripheral blood, spleen and PLN of patients with T1D and nondiabetic control organ donors, as well as from peripheral blood of living T1D patients and their relatives with risk for developing T1D (from 18 to 66 years of age). While Tfr cells were unaltered in blood, we found them reduced in spleen and PLN of patients with T1D compared to non-diabetic controls. In mice, adoptive transfer of BDC2.5 Tfh cells alone into NOD.SCID animals induced T1D while co-transfer of Tfr cells delayed disease development. These results suggest that a reduction in Tfr cells in SLO of humans with T1D might contribute toward the generation of islet-specific AAbs due to a reduced regulation in Tfh-B cell interactions. 


\section{Research Design and Methods}

\section{Subjects and data collection}

Human blood and tissue collection were conducted under protocols approved by the San Raffaele Hospital Ethics Committee and a University of Florida Institutional Review Board (IRB) approved exempt human subjects' protocol. Peripheral blood was collected from adults in groups shown in Supplementary Tables 1-2. Spleen and PLN were derived from brain dead non-diabetic donors (controls) of the San Raffaele Hospital islet transplantation program and from T1D donors from the Network for Pancreatic Organ donors with Diabetes (nPOD). A summary and detailed list of organ donors used in this study are provided in Supplementary Tables 3-5. Patients with T1D were positive for at least one islet-specific AAb (GAD65, insulin (IAA), ICA, ZnT8, IA-2; Supplementary Table 2). Relatives of patients with T1D enrolled in the Type 1 Diabetes TrialNet Pathway to Prevention Trial (TN01 Trial) were screened for islet specific AAb and considered at-risk for developing T1D. Subjects were tested for five islet-specific AAb (GAD65, IAA, ICA, ZnT8, IA-2) and were classified as: AAbsubjects; positive for one AAb (1 AAb+); stage $1 \mathrm{~T} 1 \mathrm{D}$, subjects with two or more islet AAbs $(\geq 2 \mathrm{AAb}+)$ and normal glucose tolerance test (GTT); and, stage $2 \mathrm{~T} 1 \mathrm{D}$, subjects with two or more islet $\mathrm{AAbs}(\geq 2 \mathrm{AAb}+)$ and impaired GTT (32).

\section{Flow Cytometry}

Whole blood, peripheral blood mononuclear cells (PBMCs) and single cell suspensions from spleen and PLN were prepared as previously described (33). Immune populations were stained with a combination of antibodies specific for human CD45 (REA747), CD4 (SK3), CD3 (SK7), CXCR5 (RF8B2), CD25 (2A3), CD19 (4G7), CD8 (BW135/80), CD14 (TUK4), CXCR3 (IC6), CCR6 (G034E3), CD45RA (REA562), PD-1 (eBioJ105), and ICOS (ISA-3) for 20 minutes at room temperature (RT) (Supplementary Table 6, Panels A, B and C). Erythrocytes in stained whole blood with EDTA were lysed with ACK, washed, and cells fixed in PBS with $0.4 \%$ PFA. PBMCs were isolated from heparinized venous blood by density gradient centrifugation using Lymphoprep (STEMCELL) according to manufacturer's instructions. Stained PBMCs, spleen, and PLN were fixed-permeabilized with a FOXP3 Fixation kit (eBiosciences) and stained for FOXP3 (259D) according to manufacturer's instructions. Cells were acquired on a FACS Canto II (BD Biosciences) and analyzed with FlowJo software (v10 BD Bioscience). Detailed staining panels are listed in Supplementary Table 6. Whole blood was used to analyze Tfh cell subsets (CXCR3 ${ }^{+}$CCR6- Tfh1, CXCR3- 
CCR6- Tfh2, CXCR3-CCR6 ${ }^{+}$Tfh 17 and CXCR3 ${ }^{+}$CCR6 ${ }^{+}$Tfh $1 / 17$ cells, and PD- ${ }^{+}$CXCR3- Tfh cells). PBMCs were used to analyze Tfh, Tfr and CXCR5-Treg cells.

\section{Immunofluorescence}

PLN from subjects with T1D and controls (Supplementary Table 5) were fixed with formalin, embedded in paraffin, cut to $5 \mu \mathrm{m}$ sections, mounted on slides, and dried for 24 hours. Slides were permeabilized with confocal buffer for 1 hour, washed with PBS, blocked with mouse and/or goat serum for 1 hour and then, incubated with primary antibodies overnight at $4^{\circ} \mathrm{C}$ (Supplementary Table 7). Slides were washed 3 times for 15 minutes in PBS and stained with secondary antibodies for 2 hours (Supplementary Table 7). Tissues were stained with a nuclear marker (JoPro) at a 1:15,000 dilution for 20 minutes, then mounted with Fluoromont G mounting media (company). A Nikon (A1) confocal microscope utilizing NIS-Elements AR software was used to capture z-stacked images (512x512 pixels) of PLN. The "live un-mixing" function in NIS-Elements AR software was used for compensation of the emitted fluorescence, with the emission spectrum from single-stained tissues used to separate the fluorescence into corresponding channels. Further quantitative imagining analysis was performed by Histocytometry as previously described on 3 serial tissue sections of PLN (34).

\section{CXCL13 plasma levels evaluation}

Whole peripheral blood (EDTA) was centrifuged at 1,000 rpm for 15 minutes and plasma collected. Plasma was further centrifuged at 13,000 rpm for 10 minutes to remove any debris. CXCL13 was evaluated in plasma by ELISA assay (Human CXCL13/BLC/BCA-1 Quantikine ${ }^{\circledR}$ ELISA Kit, R \& D Systems) following the manufacturer's instructions.

\section{Mice}

NOD-SCID and BDC2.5 mice were maintained in a specific pathogen-free barrier in the animal facility at San Raffaele University. Mouse splenocytes were sorted on a FACS Aria II Sort flow cytometer, washed and resuspended in sterile PBS. $2.5 \times 10^{5} \mathrm{CD}^{+} \mathrm{Tfh}\left(\mathrm{CXCR} 5^{+} \mathrm{CD} 25^{-}\right)$cells from BDC2.5 mice, with or without $2.5 \times 10^{5} \mathrm{BDC} 2.5 \mathrm{CD}^{+} \mathrm{CXCR} 5^{+} \mathrm{CD} 25^{+} \mathrm{Tfr}$ cells, as indicated were injected intravenously (i.v.) into NOD-SCID recipients. B cells from normoglycemic NOD mice were isolated with CD19 B cells Isolation Kit (MACS) and $3 \times 10^{6}$ cells were co-injected i.v. Mice were monitored for diabetes by measurement of blood glucose 
twice per week. Diabetes was defined as two consecutive readings above $11.1 \mathrm{mM}$. All animal experiments were reviewed and approved by the Institutional Animal Care and Use Committee (IACUC) of San Raffaele University.

\section{Pancreas H\&E}

Pancreata were collected either when mice turned diabetic or 30 days after adoptive transfer, when control, BDC2.5 Tconv-treated mice first turned diabetic. After being placed in 4\% formalin, pancreata were embedded in paraffin and stained with hematoxylin and eosin (H\&E) as previously described (35).

\section{Statistics}

Quantitative data are expressed as mean, and categorical data expressed as n (percentage). Normality of distribution was assessed using the Shapiro-Wilks test. Non-parametric tests were used for analysis. Comparisons between two groups were performed using Mann Whitney U test. Comparisons among more than two groups were performed using Kruskal-Wallis test with Dunn's post-test for multiple comparisons. Long-rank Mantel-Cox test was used for multiple comparisons of murine data. Spearman's correlation coefficient was computed to study the strength of correlation between quantitative variables. Statistical analyses were performed using GraphPad Prism software version 7. A $p$-value less than 0.05 was considered significant.

\section{Data and Resource Availability}

The data sets generated during and/or analyzed during the current study are available from the corresponding author upon reasonable request. 


\section{Results and Discussion}

\section{Blood Tfh and Tfr cells in AAb+ adult subjects with and without clinical T1D}

The role of islet-specific AAbs that are usually detected months to several years before the clinical onset of T1D in humans remains unknown. Tfh cells control Ig production from B cells. Alterations in Tfh cell function and/or their regulation by Tfr cells were shown to associate with the presence of islet-specific AAbs in humans with presymptomatic and diagnosed T1D (22,36,37). Here, we determined the frequency of Tfh and Tfr cells in living subjects with T1D, their first- and second-degree relatives and control subjects recruited through TrialNet Milan and from the San Raffaele Hospital (donors are described in Supplementary Tables 1-2). The frequency of circulating Tfh $\left(\mathrm{CXCR}^{+} \mathrm{FOXP} 3^{-}\right)$, Tfr $\left(\mathrm{CXCR}^{+} \mathrm{FOXP}^{+}\right)$, and conventional $\mathrm{CXCR}^{-}$- Treg $\left(\mathrm{CXCR} 5-\mathrm{FOXP} 3^{+}\right)$cells was determined in AAb-negative $(n=14)$, AAb-positive $(n=26)$, and T1D subjects $(n=34)$ after gating on total $\mathrm{CD}^{+} \mathrm{CD}^{+}$(CD19-CD8-CD14-) cells, as we previously described (25). We and others previously showed that $\mathrm{CXCR}^{+} \mathrm{CD} 4 \mathrm{~T}$ cells are either $\mathrm{CD}^{-} 5 \mathrm{RA}^{-}$or $\mathrm{CD}^{-} 5 \mathrm{RA}^{\text {int }}$ suggesting they are memory or antigen-experienced $(38,39)$. Hence, no CD45RA- gating step was included in the analysis. While the frequency of circulating Tfr cells was similar in all groups, the frequency of Tfh cells was lower in individuals with T1D compared to age-matched AAb+ subjects (mean \pm SD of $19.93 \pm 7.92 \%$ vs $26.24 \pm 6.38 \%$, respectively) (Fig. 1A-B). Years with T1D were not significantly associated with the distribution of Tfh, Tfr and CXCR5- Treg cells (Supplementary Fig. 1A). Altered Tfh/Tfr cell ratios have been associated with an increased prevalence of AAbs in autoimmune BXD2 mice (40). By analyzing the Tfh/Tfr in our cohort, we found no differences among the groups (Fig. 1B).

Although the frequency of Tfr cells was similar between AAb-, AAb+ and subjects with T1D, we sought to evaluate potential differences in the levels of the remaining (non-Tfr) Treg cells. The frequencies of conventional CXCR5-FOXP3 ${ }^{+}$Treg were similar between AAb+ subjects and patients with $\mathrm{T} 1 \mathrm{D}$, but higher in $\mathrm{AAb}+$ subjects $(7.51 \pm 2.77 \%)$ as compared to $\mathrm{AAb}$ - controls $(5.06 \pm 2.20 \%)$, possibly as a consequence of active autoimmunity in $\mathrm{AAb}+$ individuals in advance of metabolic dysfunction (Fig. 1C). We further divided the AAb+ subjects into stage 1 and stage 2 T1D (32) and assessed the distribution of circulating Tfr and Tfh cells according to this classification, but no differences were seen even when compared to AAb- and T1D groups (Supplementary Fig. 1B). Specific genetic alleles of the human leukocyte antigen (HLA) are strongly associated with increased susceptibility to T1D (41). Class II HLA haplotypes that confer increased risk to develop T1D are HLA-DRB1*03 (DR3), 
and HLA-DRB1*04 (DR4), with subjects heterozygous for DR3/DR4 having the highest-risk (42). We analyzed the proportion of Tfh, Tfr, CXCR5- Treg and total Treg cells in our cohort of non-diabetic AAb+ TrialNet subjects that were HLA-DRX/DRX (i.e., neither HLA-DR3 nor HLA-DR4, $n=6)$, DR3/DRX ( $n=9)$, DR4/DRX $(n=4)$ or DR3/DR4 $(n=4)$. We found a trend of higher Tfr cell frequency in HLA-DR3/DR4 AAb+ subjects compared to HLA-DRX/DRX subjects (Supplementary Fig. 1C).

Elevated CXCL13 plasma levels, a marker of GC activity, have been shown to correlate with the relative frequency of circulating Tfh cells (43). Consistent with the lower circulating frequency of Tfh cells in our T1D subjects, we found lower plasma CXCL13 levels in individuals with T1D compared to non-diabetic AAb- and at-risk AAb+ subjects $(24.85 \pm 18.22$ $\mathrm{pg} / \mathrm{mL}$ T1D vs $57.94 \pm 40.19 \mathrm{pg} / \mathrm{mL}$ AAb- vs $46.45 \pm 32.66 \mathrm{pg} / \mathrm{mL}$ AAb+, Fig. 1D). Plasma CXCL13 levels associated positively with the frequency of Tfr cells, but not with that of the Tfh nor CXCR5-Treg cells nor the Tfh/Tfr cell ratio (Supplementary Fig. 1D).

Circulating Tfh cells are composed of phenotypically and functionally distinct subsets based on the expression of the CXCR3 and CCR6 chemokine receptors with each Tfh subset displaying distinct capacities to help B cells $(18,19)$. Here, we determined the frequencies of Tfh1, Tfh2, Tfh 17 and CXCR $3{ }^{+}$CCR6 ${ }^{+}$Tfh $1 / 17$ cells in the same cohort of adult subjects (using whole blood). We found that Tfh1/17 cell frequency was higher, while Tfh 2 cell frequency was lower in patients with T1D in comparison AAb+ subjects (Supplementary Fig. 2A-B). We also examined the frequency of $\mathrm{PD}-1^{+} \mathrm{CXCR} 3^{-}$Tfh cells, which were found to strongly correlate with the production of neutralizing antibodies in HIV patients (44). Although AAb+ subjects had a slightly elevated frequency of PD- $1^{+} \mathrm{CXCR} 3^{-} \mathrm{Tfh}$ cells, there were no significant differences among any of the groups (Supplementary Fig. 2C-D). No differences in Tfh1, 2 17 or PD $-1^{+}$CXCR3- Tfh cells were observed when $\mathrm{AAb}+$ subjects were divided according to their disease stage or HLA type (data not included).

Next, we assessed the functional competence of Tfh cells from the blood of living control $(n=19)$ and T1D subjects $(n=9)$ in co-culture experiments with naïve or memory B cells stimulated with Staphylococcal enterotoxin B (SEB, Fig. 1E). No differences in plasmablast $\left(\mathrm{CD} 20^{-} \mathrm{CD} 38^{+}\right)$differentiation or IgG and $\mathrm{IgM}$ production were seen from either naïve or memory responder B cells, showing that T1D and control-derived Tfh cells were similarly potent at providing B-cell help (Fig. 1E-F). As expected, memory B cells produced higher levels of IgG and IgM compared to naïve B cells cultured with Tfh cells (Fig. 1F).

The pathological role of islet-specific AAbs detected months to several years before the clinical onset of T1D in humans is unknown. Tfh cells control Ig production from B cells. 
Therefore, alterations in Tfh cell function and/or their regulation by Tfr cells likely contribute to the presence of islet-specific AAbs in humans with presymptomatic and diagnosed T1D. Our data confirmed alterations in blood $\mathrm{Tfh}$ cells of presymptomatic $\mathrm{AAb}+$ individuals reported previously (45), showing that peripheral blood of adults with islet-specific AAbs had a higher frequency of Tfh cells, even compared to T1D patients. One report showed that circulating Tfh cells were also increased in children with stage 2 but not stage 1 presymptomatic T1D (13).

Contrary to a previous report showing increased circulating Tfr in T1D patients (pooled adults and children) (36), no significant alterations in circulating Tfr cells were observed in our cohort of adults reported here. Viisanen et al on the other hand, found an increase in circulating Treg cells but not Tfr cells in children with newly diagnosed T1D (46). We previously described an expansion of circulating Tfr cells expressing reduced levels of PD-1 in children with T1D $(13,47)$. These results suggest that T1D immunopathogenesis might be different in children as compared to adults, as it has been previously speculated (48-50). Differences between our study and those previously reported (13) and (36) may be due to different gating strategies, cohorts, age distribution, and duration of T1D.

\section{Human Tfr cells are highly enriched in PLN as compared to spleen and blood in control donors}

Tfh and Tfr cells are most commonly identified in SLOs, including tonsils, spleen, and LN where they interact with B cells during the GC response (51). Although more easily accessible, peripheral blood Tfh and particularly Tfr cells may not accurately represent their counterparts in SLOs (52). Thus, we determined the frequency of $\mathrm{Tfh}$ (CXCR5 $\left.{ }^{+} \mathrm{FOXP3} 3^{-}\right)$, Tfr $\left(\mathrm{CXCR}^{+} \mathrm{FOXP}^{+}\right)$, and $\mathrm{CXCR}^{-}$Treg $\left(\mathrm{CXCR}^{-} \mathrm{FOXP}^{+}\right)$cells in PLN and spleen of 15 nondiabetic control organ donors (aged 39-64 years) as compared to PBMCs from 26 living healthy control subjects (HC, aged 18-46 years). Spleen and PLN samples were derived from the same donors (Supplementary Table 3) (all samples derived from our hospital). With the caveat that blood samples derived from living donors while spleen and PLN from deceased donors, we found an increased frequency of Tfr cells in PLN as compared to spleen and blood (mean $\pm \mathrm{SD}$ $11.86 \pm 4.28 \%$ PLN vs $2.02 \pm 1.26 \%$ Spleen vs $1.66 \pm 1.14 \%$ PBMC; Fig. 2A-B), suggesting that the PLN could be an important immune checkpoint site. We further found that the frequency of CXCR5- Treg cells in the PLN, spleen and blood were similar (Fig. 2C). The Tfh/Tfr ratio was significantly lower in PLN (2.46 \pm 1.3 PLN vs $16.19 \pm 12.06$ Spleen vs $24.8 \pm 23.01$ PBMC). 
We also found that the expression of PD-1 on Tfr, Tfh and CXCR5- Treg was highest in spleen followed by PLN and lowest in PBMC (Fig. 2D-E).

Similarly to Kumar et al (27), we found a predominant presence of Tfr cells, but not Tfh, and increased PD-1 expression by Tfr cells in the spleen and PLN of non-diabetic controls in comparison to blood of non-diabetic individuals. Our observations suggest that Tfr cells in spleen and PLN possibly play an important role in regulating self-tolerance and inflammation.. To date, no studies related to T1D have addressed Tfh and Tfr cells in human tissues other than the blood. Next, we analyzed Tfh and Tfr cells in spleen and PLN of patients with T1D.

\section{Tfr cells are decreased in spleen and PLN of patients with T1D}

Immunophenotyping and histological studies of SLOs, including spleen and PLN, from patients with T1D are very limited (53). Willcox et al. have shown decreased primary B cell follicle frequency and fewer follicular DC networks in PLN from patients with recent-onset T1D (31), but did not explore what role Tfr cells may have played. To gain further insights into the distribution Tfh, Tfr and CXCR5- Treg cells in these tissues, we performed flow cytometry and histological studies in spleen and PLN from non-diabetic (control, $n=15$ for flow cytometry, $n=8$ for histological studies) and T1D ( $n=9$ for flow cytometry, $n=8$ for histological studies) cadaveric donors (Supplementary Tables 4 \& 5). Compared to controls, Tfr cells were reduced in spleen (mean \pm SD $2.02 \pm 1.26 \%$ control vs. $0.63 \pm 0.52 \%$ T1D) and PLN (11.86 $\pm 4.28 \%$ control vs. $6.02 \pm 7.32 \%$ T1D) of T1D subjects (Fig. 3A-B), while Tfh cell frequency was similar between T1D and control subjects (Fig. 3A-B). CXCR5- Treg cells were also reduced in PLN and spleen of subjects with T1D compared to controls, but the difference was not significant in the flow cytometry study (Fig. 3A-B). A caveat in this analysis is the use of two different cohorts, where the T1D derived exclusively from nPOD, likely collected and processed differently at several sites partly explaining the great variability in the results. Another caveat is the age difference between T1D and the control cohorts, with the controls being much older overall (Supplementary Table 4). Hence, we undertook a histological analysis of PLN and analyzed two cohorts (T1D vs. non-T1D) that were more similar in age (Supplementary Table 5). Of note, we observed that the youngest T1D $(7.37 \% \pm 8.18)$ and oldest control $(12.56 \% \pm 3.99)$ samples do not represent extremes in phenotype. Furthermore, older T1D $(1.75 \% \pm 1.56)$ and younger control $(15.4 \% \pm 0.9)$ samples are not similar. The Tfr frequency in older T1D (average age: 48yo) is $1.75 \% \pm 1.56$, much lower than the one seen in younger controls (average age: $44.5 \mathrm{yo})$ is $15.4 \% \pm 0.9$ in PLN. In spleen, the oldest T1D (0.5\% $\pm 0.31)$ have similar Tfr frequency compared to youngest controls $(0.54 \% \pm 0.19)$. 
The relative decrease in $\mathrm{Tfr}$ cells in patients with T1D was confirmed by immunofluorescence in the PLN tissue (Fig. 3C). In this study, B cell follicles (CD20 $0^{+}$areas) and $\mathrm{T}$ cell zones $\left(\mathrm{CD} 20^{-} \mathrm{CD} 4^{+}\right.$areas) in human PLN were analyzed. Since CXCR5 was not used in the IFS staining, FOXP $3^{+} \mathrm{CD}^{+} \mathrm{T}$ cells in follicles were considered as $\mathrm{Tfr}$ cells and FOXP3-PD $-1^{+} \mathrm{T}$ cells as Tfh cells. Similarly, FOXP3 ${ }^{+}$and FOXP3- CD4 T cells were considered conventional Treg and T helper cells in the T-cell zone, respectively. Arrows in Fig. 3C (top left) show Treg cells $\left(\mathrm{CD}^{+} \mathrm{FOXP}^{+}\right)$localized in B cell follicles of a control tissue. We found that the number of FOXP $3^{+}$cells were lower in the follicles of PLN from T1D donors compared to controls, while there were no differences in the number of CD4 $4^{+} \mathrm{FOXP} 3-\mathrm{PD}-1^{+}$ cells (Fig. 3D). We also calculated the number of $\mathrm{CD}^{+}{ }^{+} \mathrm{FOXP} 3^{+}$Treg cells in the T-cell zone (Fig. 3C). Interestingly, the number of Treg cells in the $\mathrm{T}$ cell zone was also lower in T1D donors (Fig. 3E). Thus, our results show that the distribution of $\mathrm{Tfr}\left(\mathrm{CD}^{+} \mathrm{FOXP}^{+}\right)$cells is reduced within the $\mathrm{B}$ cell follicles of PLN from T1D donors, which could impact the architectural structure of B cell follicles and cause abnormal generation of islet-specific AAbs. Of note, different studies have reported that depletion of Treg in mouse models causes an increase in antigen-specific Tfh cells in LN and circulating AAbs, including anti-dsDNA $(15,16,54)$, suggesting that Tfr cells might be involved in islet specific AAb insurgence and T1D progression.

\section{Tfr cells can delay disease onset in a mouse model of T1D}

Next, to address the role of Tfr cells in T1D development, we tested their ability to regulate T1D in an adoptive transfer mouse model of the disease (55) (Supplementary Fig. 3A for sorting gating strategy). First, we examined whether Tfh-like $\left(\mathrm{CXCR}^{+} \mathrm{CD} 25^{-}\right)$cells isolated from the spleens of BDC2.5 transgenic mice were able to induce T1D in NOD-SCID mice, similarly to conventional (CXCR5-CD25-) T (Tconv) cells isolated from the same donors (Supplementary Fig. 3B-C for frequencies of Tfh- and Tfr-like cells in the spleen of BDC2.5 mice). BDC2.5 Tfh cells were as potent as BDC2.5 Tconv cells at inducing T1D in NOD-SCID mice (Fig. 4A). Interestingly, co-transfer of Tfr-like cells isolated from BDC2.5 mice substantially delayed but not protected against T1D onset in NOD-SCID mice (Fig. 4A). In contrast to conventional BDC2.5 Treg cells (Fig. 4A), Tfr-like cells were unable to offer permanent protection from the disease (Fig. 4A). Analysis of transferred cells showed presence of FOXP $3^{+}$Treg cells in mice injected with $\mathrm{CXCR}^{-}$and $\mathrm{CXCR}^{+} \mathrm{CD} 25^{+} \mathrm{BDC} 2.5$ Treg cells (Supplementary Fig. 3D-E), suggesting that Tfr-like cells possibly downregulated CXCR5 
but maintained FOXP3 expression under these experimental conditions. Histological analysis of the pancreata 30 days after adoptive transfer, revealed destructive insulitis in mice treated with Tconv or Tfh alone, while Treg of Tfr co-transfer provided protection (Fig. 4B).

The functional differences between murine Tfr and Treg cells might have been due to their FOXP3 content, stability, mechanism of function, trafficking or the pathogenicity/Treg resistance of the effectors. Xu et al. performed a similar experiment transferring Tfr cells sorted from prediabetic NOD mice into NOD-SCID mice and similarly found that Tfr cells could prevent T1D (36). In a different mouse model, Kenefeck et al. transferred DO11 T cells enriched in CXCR5 expression into RIP-mOVA-expressing mice, thereby demonstrating that Tfh cells can transfer diabetes and cause pancreas infiltration (22). Similarly, our results indicate that Tfh-like cells sorted from BDC2.5 mice have diabetogenic function and, importantly, Tfr cells can delay it. These results further suggest that Tfr cells are needed to maintain peripheral tolerance by regulating diabetogenic $\mathrm{Tfh}$ and $\mathrm{B}$ cells, and that their absence might potentiate the onset of T1D. Thus, Tfr cell adoptive cell therapy should be explored as a potential treatment to prevent T1D.

In conclusion, our findings support the hypothesis that the reduction of tissue-resident Tfr cells might be at the root of a failed peripheral tolerance, leading to the activation of isletspecific Tfh cells and the production of AAbs in human T1D. Further studies of tissue-resident Tfr cells in $\mathrm{AAb}+$ subjects are needed to reveal their possible role in AAb production and disease pathogenesis. Therefore, our data provide significant evidence for a regulatory role for Tfr cells in preventing progression to T1D and provide support for exploring Tfr cells as potential therapeutic modalities to treat T1D. 


\section{Disclosures}

The authors declare no competing financial interests.

\section{Author contributions}

AV performed experiments, analyzed data and wrote the manuscript TJ, JG, KS, RDF, GG, EI, AS, HRS, MF, GM, AS and FR performed experiments, PG, EB, CB, AL, AC, RN, RM, EB, LP, collected samples and contributed to discussion, MPC, AA and MB discussed data, ND, $\mathrm{CP}$ and TB discussed data, reviewed/edited the manuscript, GF performed experiments, analyzed data and wrote the manuscript. GF is the guarantor for the work as a whole, including the study design, access to data, and the decision to submit and publish the manuscript.

\section{Acknowledgements}

Samples from at-risk subjects were obtained through a TrialNet ancillary study to the TN-01 Pathway to Prevention study funded by NIH grants (U01 DK061010, U01 DK061034, U01 DK061042, U01 DK061058, U01 DK085465, U01 DK085453, U01 DK085461, U01 DK085463, U01 DK085466, U01 DK085499, U01 DK085504, U01 DK085505, U01 DK085509, U01 DK103180, U01-DK103153, U01-DK085476, U01-DK103266 and P01 AI42288 and to TMB)) and Helmsley Charitable Trust and JDRF International. This work was funded by Young Researchers Award by the Italian Ministry of Health to G. Fousteri (GR2011-02348732). This research was performed with the support of the Network for Pancreatic Organ donors with Diabetes (nPOD; RRID:SCR_014641), a collaborative type 1 diabetes research project sponsored by JDRF (nPOD: 5-SRA-2018-557-Q-R) and The Leona M. \& Harry B. Helmsley Charitable Trust (Grant\#2018PG-T1D053). The content and views expressed are the responsibility of the authors and do not necessarily reflect the official view of nPOD. Organ Procurement Organizations (OPO) partnering with nPOD to provide research resources are listed at http://www.jdrfnpod.org/for-partners/npod-partners/

We would like to thank Bechara Mfarrej and Mariagrazia Favellato for help with FACS staining and all nurses from the Pediatric Department at the San Raffaele Hospital for help with blood collection. We thank Amanda Posgai Simmons for help with editorial assistance.

\section{References}

1. Van Belle TL, Coppieters KT, Von Herrath MG. Type 1 Diabetes: Etiology, Immunology, and Therapeutic Strategies. Physiol Rev. 2011;

2. Mallone R, Brezar V, Boitard C. T cell recognition of autoantigens in human type 1 diabetes: clinical perspectives. Clin Dev Immunol. 2011; 
3. Ziegler AG, Rewers M, Simell O, Simell T, Lempainen J, Steck A, et al. Seroconversion to multiple islet autoantibodies and risk of progression to diabetes in children. JAMA - J Am Med Assoc. 2013;

4. Crotty S. Follicular helper CD4 T cells (TFH). Annu Rev Immunol. 2011;

5. Victora GD; Nussenzweig MC. Germinal Centers. Annu Rev Immunol. 2012;

6. Stebegg M, Kumar SD, Silva-Cayetano A, Fonseca VR, Linterman MA, Graca L. Regulation of the germinal center response. Frontiers in Immunology. 2018.

7. Mesin L, Ersching J, Victora GD. Germinal Center B Cell Dynamics. Immunity. 2016.

8. Schaerli P, Willimann K, Lang AB, Lipp M, Loetscher P, Moser B. CXC chemokine receptor 5 expression defines follicular homing T cells with B cell helper function. $\mathrm{J}$ Exp Med. 2000;

9. Breitfeld D, Ohl L, Kremmer E, Ellwart J, Sallusto F, Lipp M, et al. Follicular B Helper T Cells Express Cxc Chemokine Receptor 5, Localize to B Cell Follicles, and Support Immunoglobulin Production. J Exp Med. 2000;

10. Bryant VL, Ma CS, Avery DT, Li Y, Good KL, Corcoran LM, et al. CytokineMediated Regulation of Human B Cell Differentiation into Ig-Secreting Cells: Predominant Role of IL-21 Produced by CXCR5+ T Follicular Helper Cells. J Immunol. 2007;

11. Choi YS, Kageyama R, Eto D, Escobar TC, Johnston RJ, Monticelli L, et al. ICOS Receptor Instructs T Follicular Helper Cell versus Effector Cell Differentiation via Induction of the Transcriptional Repressor Bc16. Immunity. 2011;

12. Locci M, Havenar-Daughton C, Landais E, Wu J, Kroenke MA, Arlehamn CL, et al. Human circulating PD-1+CXCR3-CXCR5+ memory Tfh cells are highly functional and correlate with broadly neutralizing HIV antibody responses. Immunity. 2013;

13. Viisanen T, Ihantola EL, Näntö-Salonen K, Hyöty H, Nurminen N, Selvenius J, et al. Circulating CXCR5+PD-1+ICOS+Follicular T helper cells are increased close to the diagnosis of type 1 diabetes in children with multiple autoantibodies. Diabetes. 2017;

14. Fousteri G, Ippolito E, Ahmed R, Rahim Hamad A. Beta-cell Specific Autoantibodies: 
Are they Just an Indicator of Type 1 Diabetes? Curr Diabetes Rev. 2017;

15. Linterman MA, Pierson W, Lee SK, Kallies A, Kawamoto S, Rayner TF, et al. Foxp3+ follicular regulatory $\mathrm{T}$ cells control the germinal center response. Nat Med. 2011;

16. Chung Y, Tanaka S, Chu F, Nurieva RI, Martinez GJ, Rawal S, et al. Follicular regulatory T cells expressing Foxp 3 and Bcl-6 suppress germinal center reactions. Nat Med. 2011;

17. Sage PT, Sharpe AH. T follicular regulatory cells in the regulation of B cell responses. Trends in Immunology. 2015.

18. Morita R, Schmitt N, Bentebibel SE, Ranganathan R, Bourdery L, Zurawski G, et al. Human Blood CXCR5+CD4+T Cells Are Counterparts of T Follicular Cells and Contain Specific Subsets that Differentially Support Antibody Secretion. Immunity. 2011;

19. Schmitt N, Bentebibel SE, Ueno H. Phenotype and functions of memory Tfh cells in human blood. Trends in Immunology. 2014.

20. Ma J, Zhu C, Ma B, Tian J, Baidoo SE, Mao C, et al. Increased frequency of circulating follicular helper T cells in patients with rheumatoid arthritis. Clin Dev Immunol. 2012;

21. Bentebibel S-E, Lopez S, Obermoser G, Schmitt N, Mueller C, Harrod C, et al. Induction of ICOS+CXCR3+CXCR5+ TH cells correlates with antibody responses to influenza vaccination. Sci Transl Med. 2013;

22. Kenefeck R, Wang CJ, Kapadi T, Wardzinski L, Attridge K, Clough LE, et al. Follicular helper T cell signature in type 1 diabetes. J Clin Invest. 2015;

23. Dhaeze T, Peelen E, Hombrouck A, Peeters L, Van Wijmeersch B, Lemkens N, et al. Circulating Follicular Regulatory T Cells Are Defective in Multiple Sclerosis. J Immunol. 2015;

24. Miles B, Miller SM, Folkvord JM, Kimball A, Chamanian M, Meditz AL, et al. Follicular regulatory T cells impair follicular T helper cells in HIV and SIV infection. Nat Commun. 2015; 
25. Vecchione A, Gerosa J, Fonte R Di, Pia CM, Napoleone V, Ippolito E, et al. Reduced PD-1 expression on circulating CXCR5+ and CXCR5- FOXP3+ Treg cells marks type 1 diabetes initiation in children. Clin Immunol [Internet]. 2019;108319. Available from: https://doi.org/10.1016/j.clim.2019.108319

26. Fonseca VR, Agua-Doce A, Maceiras AR, Pierson W, Ribeiro F, Romão VC, et al. Human blood $\mathrm{T}_{\mathrm{fr}}$ cells are indicators of ongoing humoral activity not fully licensed with suppressive function. Sci Immunol. 2017;

27. Kumar S, Fonseca VR, Ribeiro F, Basto AP, Água-Doce A, Monteiro M, et al. Developmental bifurcation of human T follicular regulatory cells [Internet]. Vol. 6, Sci. Immunol. 2021 [cited 2021 Jun 20]. Available from: http://immunology.sciencemag.org/

28. Madec A, Rousset F, Ho S, Robert F, Thivolet C, Orgiazzi J, et al. Four IgG Anti-Islet Human Monoclonal Antibodies Isolated from a Type 1 Diabetes Patient Recognize Distinct Epitopes of Glutamic Acid Decarboxylase 65 and Are Somatically Mutated. J Immunol. 1996;

29. Ferreira RC, Simons HZ, Thompson WS, Cutler AJ, Dopico XC, Smyth DJ, et al. IL21 production by CD4+ effector T cells and frequency of circulating follicular helper $\mathrm{T}$ cells are increased in type 1 diabetes patients. Diabetologia. 2015;

30. Xu X, Shi Y, Cai Y, Zhang Q, Yang F, Chen H, et al. Inhibition of increased circulating Tfh cell by anti-CD20 monoclonal antibody in patients with type 1 diabetes. PLoS One. 2013;

31. Willcox A, Richardson SJ, Walker LSK, Kent SC, Morgan NG, Gillespie KM. Germinal centre frequency is decreased in pancreatic lymph nodes from individuals with recent-onset type 1 diabetes. Diabetologia. 2017;

32. Mahon JL, Sosenko JM, Rafkin-Mervis L, Krause-Steinrauf H, Lachin JM, Thompson C, et al. The TrialNet natural history study of the development of type 1 diabetes: Objectives, design, and initial results. Pediatr Diabetes. 2009;

33. Ferraro A, Socci C, Stabilini A, Valle A, Monti P, Piemonti L, et al. Expansion of Th17 cells and functional defects in T regulatory cells are key features of the pancreatic lymph nodes in patients with type 1 diabetes. Diabetes. 2011;60(11):2903- 
13.

34. Amodio D, Cotugno N, Macchiarulo G, Rocca S, Dimopoulos Y, Castrucci MR, et al. Quantitative Multiplexed Imaging Analysis Reveals a Strong Association between Immunogen-Specific B Cell Responses and Tonsillar Germinal Center Immune Dynamics in Children after Influenza Vaccination. J Immunol. 2018;

35. Jofra T, Galvani G, Cosorich I, De Giorgi L, Annoni A, Vecchione A, et al. Experimental colitis in IL-10-deficient mice ameliorates in the absence of PTPN22. Clin Exp Immunol. 2019;197(3).

36. Xu X, Shen M, Zhao R, Cai Y, Jiang H, Shen Z, et al. Follicular regulatory T cells are associated with $\beta$-cell autoimmunity and the development of type 1 diabetes. J Clin Endocrinol Metab. 2019;104(September):4199-213.

37. Fousteri G, Raffaele Hospital S, K Walker LS, Groom J, Hall E, Daniel C, et al. Regulation of T Follicular Helper Cells in Islet Autoimmunity. Islet Autoimmun Front Immunol [Internet]. 2018;9:1729. Available from: www.frontiersin.org

38. Edner NM, Heuts F, Thomas N, Wang CJ, Petersone L, Kenefeck R, et al. Follicular helper $\mathrm{T}$ cell profiles predict response to costimulation blockade in type 1 diabetes. Nat Immunol. 2020;

39. Pietrasanta C, De Leo P, Jofra T, Ronchi A, Pugni L, Mosca F, et al. CXCR5-CXCL13 axis markers in full-term and preterm human neonates in the first weeks of life. Vol. 51, European Journal of Immunology. 2021.

40. Ding Y, Li J, Yang PA, Luo B, Wu Q, Zajac AJ, et al. Interleukin-21 promotes germinal center reaction by skewing the follicular regulatory $\mathrm{T}$ cell to follicular helper T cell balance in autoimmune BXD2 mice. Arthritis Rheumatol. 2014;

41. Gorodezky C, Alaez C, Murguía A, Rodríguez A, Balladares S, Vazquez M, et al. HLA and autoimmune diseases: Type 1 diabetes (T1D) as an example. In: Autoimmunity Reviews. 2006.

42. Nguyen C, Varney MD, Harrison LC, Morahan G. Definition of high-risk type 1 diabetes HLA-DR and HLA-DQ types using only three single nucleotide polymorphisms. Diabetes. 2013; 
43. Havenar-Daughton C, Lindqvist M, Heit A, Wu JE, Reiss SM, Kendric K, et al. CXCL13 is a plasma biomarker of germinal center activity. Proc Natl Acad Sci. 2016;

44. Locci M, Havenar-Daughton C, Landais E, Wu J, Kroenke MA, Arlehamn CL, et al. Human circulating PD-1+CXCR3-CXCR5+memory Tfh cells are highly functional and correlate with broadly neutralizing HIV antibody responses. Immunity. 2013;

45. Ekman I, Ihantola EL, Viisanen T, Rao DA, Näntö-Salonen K, Knip M, et al. Circulating CXCR5-PD-1hi peripheral T helper cells are associated with progression to type 1 diabetes. Diabetologia. 2019;

46. Viisanen T, Gazali AM, Ihantola EL, Ekman I, Näntö-Salonen K, Veijola R, et al. FOXP3 + regulatory $\mathrm{T}$ cell compartment is altered in children with newly diagnosed type 1 diabetes but not in autoantibody-positive at-risk children. Front Immunol. 2019;10(JAN).

47. Vecchione A, Di Fonte R, Gerosa J, Jofra T, Cicalese MP, Napoleone V, et al. Reduced PD-1 expression on circulating follicular and conventional FOXP ${ }^{+}$Treg cells in children with new onset type 1 diabetes and autoantibody-positive at-risk children. Clin Immunol. 2020;211.

48. Poudel A, Savari O, Striegel DA, Periwal V, Taxy J, Millis JM, et al. Beta-cell destruction and preservation in childhood and adult onset type 1 diabetes. Endocrine. 2015;

49. Paffenbarger RSJ, Kampert JB, Lee IM, Hyde RT, Leung RW, Wing AL, et al. A Comparison of Childhood and Adult Type I Diabetes Mellitus. Med Sci Sports Exerc. 1994;314(7):605-13.

50. Gianani R, Campbell-Thompson M, Sarkar SA, Wasserfall C, Pugliese A, Solis JM, et al. Dimorphic histopathology of long-standing childhood-onset diabetes. Diabetologia. 2010;

51. Crotty S. A brief history of T cell help to B cells. Nat Rev Immunol. 2015;

52. Maceiras AR, Fonseca VR, Agua-Doce A, Graca L. T follicular regulatory cells in mice and men. Immunology. 2017.

53. Bogdani M, Johnson PY, Potter-Perigo S, Nagy N, Day AJ, Bollyky PL, et al. 
Hyaluronan and hyaluronan-binding proteins accumulate in both human type 1 diabetic islets and lymphoid tissues and associate with inflammatory cells in insulitis. Diabetes. 2014;

54. Wollenberg I, Agua-Doce A, Hernández A, Almeida C, Oliveira VG, Faro J, et al. Regulation of the Germinal Center Reaction by Foxp3 + Follicular Regulatory T Cells . J Immunol. 2011;

55. Berry G, Waldner H. Accelerated type 1 diabetes induction in mice by adoptive transfer of diabetogenic CD4+ T cells. J Vis Exp. 2013; 


\section{FIGURE LEGENDS}

FIGURE 1. Blood Tfh and Tfr cells in AAb-, AAb+ subjects and patients with T1D. (A) Representative plots of $\mathrm{CD}^{+} \mathrm{T}$ cells are divided in $\mathrm{Tfr}\left(\mathrm{CXCR}^{+} \mathrm{FOXP} 3^{+}\right), \mathrm{CXCR}^{-}$-Treg $\left(\mathrm{CXCR}^{-} \mathrm{FOXP}^{+}\right)$, and Tfh $\left(\mathrm{CXCR}^{+} \mathrm{FOXP}^{-}\right)$cells in AAb-negative $(n=14)$ and $\mathrm{AAb}-$ positive $(n=26)$ subjects, and patients with T1D $(n=34)$. (B) Frequency of $\mathrm{Tfr}$ $\left(\mathrm{CXCR}^{+} \mathrm{FOXP}^{+}\right)$, Tfh $\left(\mathrm{CXCR}^{+} \mathrm{FOXP}^{-}\right)$and ratio of $\mathrm{Tfh} / \mathrm{Tfr}$ cells. (C) Frequency of CXCR5-Treg $\left(\mathrm{CXCR}^{-} \mathrm{FOXP3}^{+}\right)$. (D) CXCL13 serum concentration in AAb-negative $(n=12)$ and AAb-positive $(n=29)$ subjects, and patients with T1D $(n=13)$. (E) Representative plots of plasmablast differentiation of naïve and memory B cells when co-cultured with Tfh from

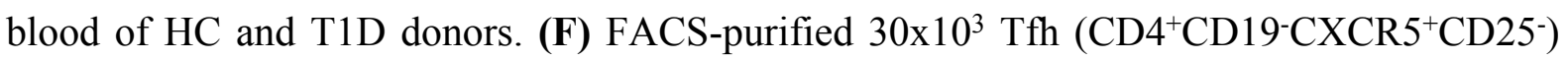
and $\mathrm{Tfr}\left(\mathrm{CD} 4^{+} \mathrm{CD} 19^{-} \mathrm{CXCR} 5^{+} \mathrm{CD} 25^{+}\right)$from blood of adult donors were co-cultured with either naïve $\left(\mathrm{CD} 27^{-}\right)$or memory $\left(\mathrm{CD} 27^{+}\right) \mathrm{B}$ cells $\left(\mathrm{CD} 19^{+} \mathrm{CD} 38^{-}\right)$and $\mathrm{SEB}$ as described in Materials and Methods. Up-regulation of CD38 and downregulation of CD20 indicates the formation of plasmablasts (PB). Pooled data from 5 experiments with 2-3 donors per group are shown. In all graphs, points represent individual donors HC $(n=12)$ and patients with T1D $(n=10)$. Differences between $\mathrm{HC}$ and T1D were analyzed with unpaired t test, while differences between memory $B$ cells $\left(B_{M}\right)$ and naïve $B$ cells $\left(B_{N}\right)$ were calculated with paired t-test. (G) ELISA determination of IgG and IgM was conducted on the culture supernatants after 7 days of co-culture. In all graphs, each point represents an individual donor with the mean and standard deviation indicated by a black line and plungers. Asterisks indicate statistical significance as calculated by Kruskal-Wallis. ${ }^{*} \mathrm{p}<0.05,{ }^{*} \mathrm{p}<0.01,{ }^{* * *} \mathrm{p}<0.001$.

FIGURE 2. Tfh and Tfr cells in the PBMCs, spleen, pancreatic LN of control donors. (A) Representative plots Tfr $\left(\mathrm{CXCR}^{+} \mathrm{FOXP3}^{+}\right)$, CXCR5-Treg $\left(\mathrm{CXCR5}-\mathrm{FOXP3} 3^{+}\right)$, and Tfh $\left(\mathrm{CXCR}^{+} \mathrm{FOXP}^{-}\right)$cells among total gated CD4+ T cells from PBMCs $(n=26)$, Spleen $(n=$ 15) and PLN $(n=15)$ of control donors. (B) Graph shows the frequency of $\mathrm{Tfr}$ $\left(\mathrm{CXCR}^{+} \mathrm{FOXP}^{+}\right)$, Tfh $\left(\mathrm{CXCR}^{+} \mathrm{FOXP} 3^{-}\right)$and ration of Tfh/Tfr cells for the PBMCs, Spleen, and pancreatic LN. (C) Graph shows the frequency of CXCR5-Treg (CXCR5-FOXP3 ${ }^{+}$). (D) Representative plots showing expression of PD-1 on Tfr $\left(\mathrm{CXCR}^{+} \mathrm{FOXP} 3^{+}\right), \mathrm{CXCR}^{-}$-Treg $\left(\mathrm{CXCR}^{-} \mathrm{FOXP}^{+}\right)$and Tfh $\left(\mathrm{CXCR}^{+} \mathrm{FOXP}^{-}\right)$cells for PBMC, Spleen and pancreatic LN of control donors. (E) Graph shows the frequency of PD-1 expression on $\mathrm{Tfr}\left(\mathrm{CXCR} 5^{+} \mathrm{FOXP} 3^{+}\right)$, CXCR5-Treg (CXCR5-FOXP3 $\left.{ }^{+}\right)$and Tfh (CXCR5'FOXP3-) cells for PBMC, Spleen and pancreatic $\mathrm{LN}$ of control donors. In all graphs, points represent individual donors with the mean 
and standard deviation indicated by a black line and plungers. Asterisks indicate statistical significance as calculated by Kruskal-Wallis. $* * * * p<0.0001, * * * \mathrm{p}<0.0001$.

FIGURE 3. Frequency of $T f h$ and $T f r$ in spleen and pancreatic $L N$ of patients with T1D.

(A) Representative plots of $\mathrm{CD}^{+} \mathrm{T}$ cells divided in $\mathrm{Tfr}\left(\mathrm{CXCR}^{+} \mathrm{FOXP} 3^{+}\right), \mathrm{CXCR}^{-}$-Treg $\left(\mathrm{CXCR}^{-\mathrm{FOXP}^{+}}{ }^{+}\right)$, and $\mathrm{Tfh}\left(\mathrm{CXCR}^{+} \mathrm{FOXP}^{-}\right)$cells for spleen and pancreatic LN of nondiabetic $(n=15)$ and T1D $(n=7)$ donors. (B) Graph shows frequencies Tfr $\left(\mathrm{CXCR}^{+} \mathrm{FOXP} 3^{+}\right)$, CXCR5-Treg (CXCR5-FOXP3 $\left.{ }^{+}\right)$, and Tfh $\left(\mathrm{CXCR}^{+}{ }^{+} \mathrm{FOXP} 3^{-}\right)$cells for spleen and pancreatic LN of non-diabetic and T1D donors. (C) Multiple IFS performed for CD20, CD4, FOXP3 and PD-1 in 3 serial tissue sections of pancreatic LN from non-diabetic $(n=8)$ and T1D $(n=8)$ donors. Confocal imagines (40x) showing the follicle $\left(\mathrm{CD} 20^{+}\right)$and TCZ (CD20-) areas of pancreatic LN. (D) Quantification of CD4 ${ }^{+} \mathrm{PD}-1^{+}$(Tfh) cells and $\mathrm{FOXP3}^{+}$(Tfr) cells per area (in $\mathrm{mm}^{3}$ ) within the Follicle. (E) Quantification of CD4 $4^{+} \mathrm{PD}-1^{+}$(T Helper) cells and FOXP3 ${ }^{+}$ ( $\mathrm{T}$ regulatory) cells per area (in $\mathrm{mm}^{3}$ ) within the TCZ. Mean (black horizontal line) and standard deviation is shown for each group. In all graphs, points represent individual donors. Asterisks indicate statistical significance as calculated by Kruskal-Wallis. ${ }^{*} \mathrm{p}<0.05,{ }^{*} \mathrm{p}<0.01$, and $* * * \mathrm{p}<0.0001$

FIGURE 4. Adoptive transfer of Tfr cells prevents diabetes in NOD/SCID mice. (A) A total of $2.5 \times 10^{5} \mathrm{CD} 4+\mathrm{TCR} \mathrm{V} \beta 4$ Tcon $\left(\mathrm{CXCR} 5^{-\mathrm{CD}} 25^{-}\right)$cells (group a, $n=6$ ) or $\mathrm{Tfh}$ $\left(\mathrm{CXCR}^{+} \mathrm{CD} 25^{-}\right)$cells (group b, $\left.n=5\right)$ with or without $2.5 \times 10^{5}$ Treg $\left(\mathrm{CXCR} 5^{-} \mathrm{CD} 25^{+}\right)$cells (group c, $n=4)$ or Tfr $\left(\mathrm{CXCR} 5^{+} \mathrm{CD} 25^{+}\right)$cells (group d, $n=6$ ) from BDC2.5 mice and $3 \mathrm{x}$ $10^{6} \mathrm{CD} 19^{+} \mathrm{B}$ cells from NOD mice, were adoptively transferred into NOD/SCID mice. The incidence of diabetes in NOD/SCID recipients over the adoptive transfer period (Kaplan Meier curve). The graph shows data is pooled from two independent experiments. In all graphs, points represent individual mice. Asterisks indicate statistical significance as calculated by KruskalWallis. ${ }^{* *} \mathrm{p}<0.01$. Long-rank Mantel-Cox test was used to determine significance in diabetesfree curve. (B) Representative haematoxylin and eosin (H\&E) pancreata sections from mice that received adoptive transfer ( $n=3$ /group) 30 days after AT. Scale bars: $300 \mu \mathrm{m}$, high-power fields. 


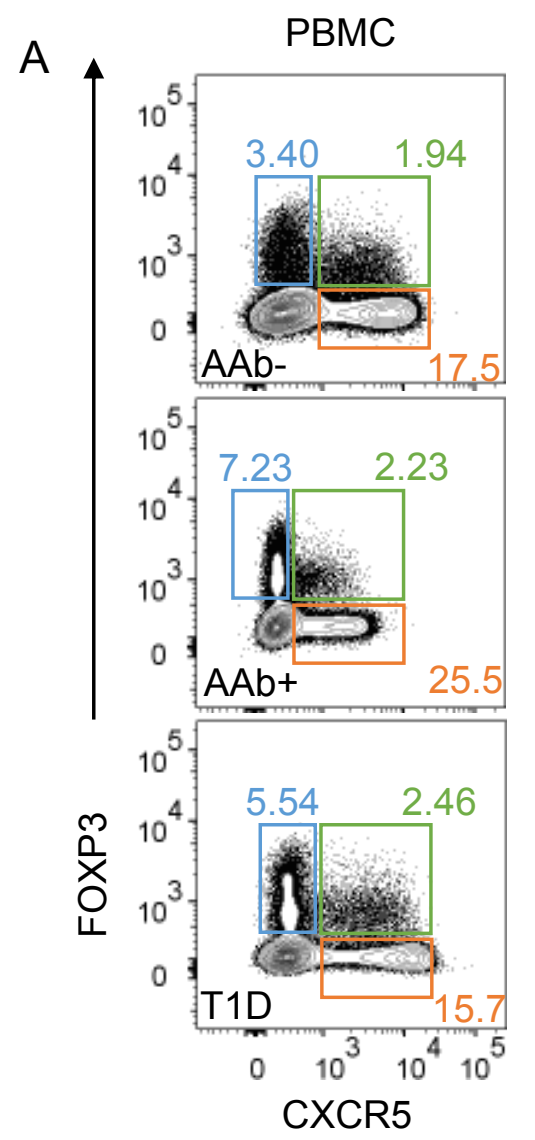

B
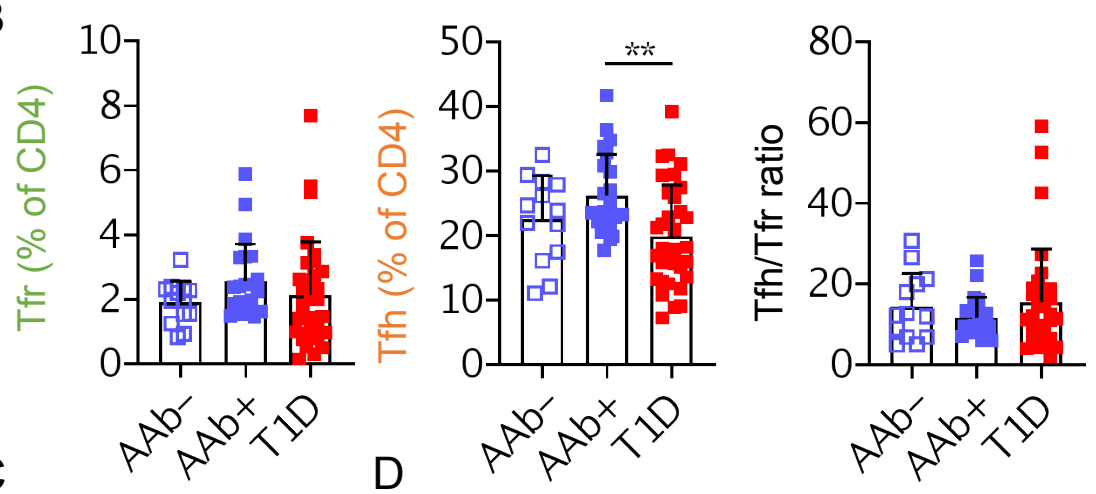

C
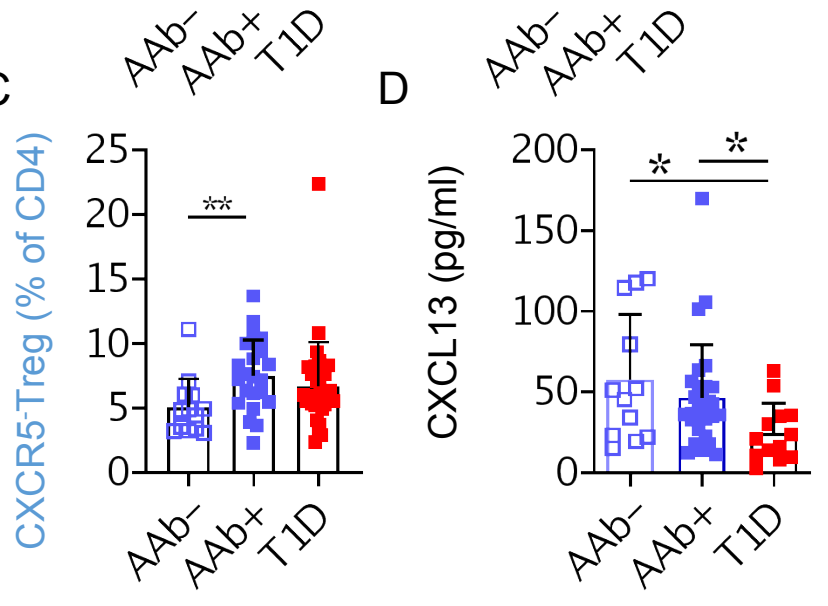

E

Control

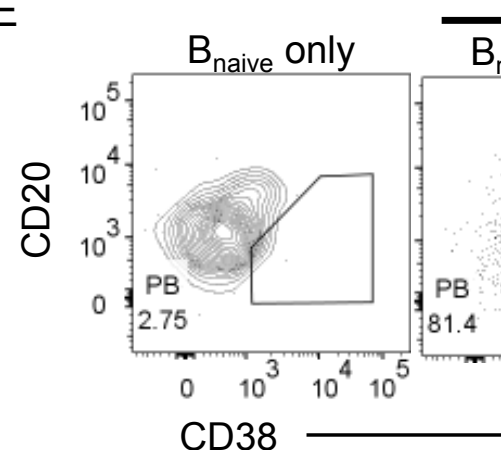

F
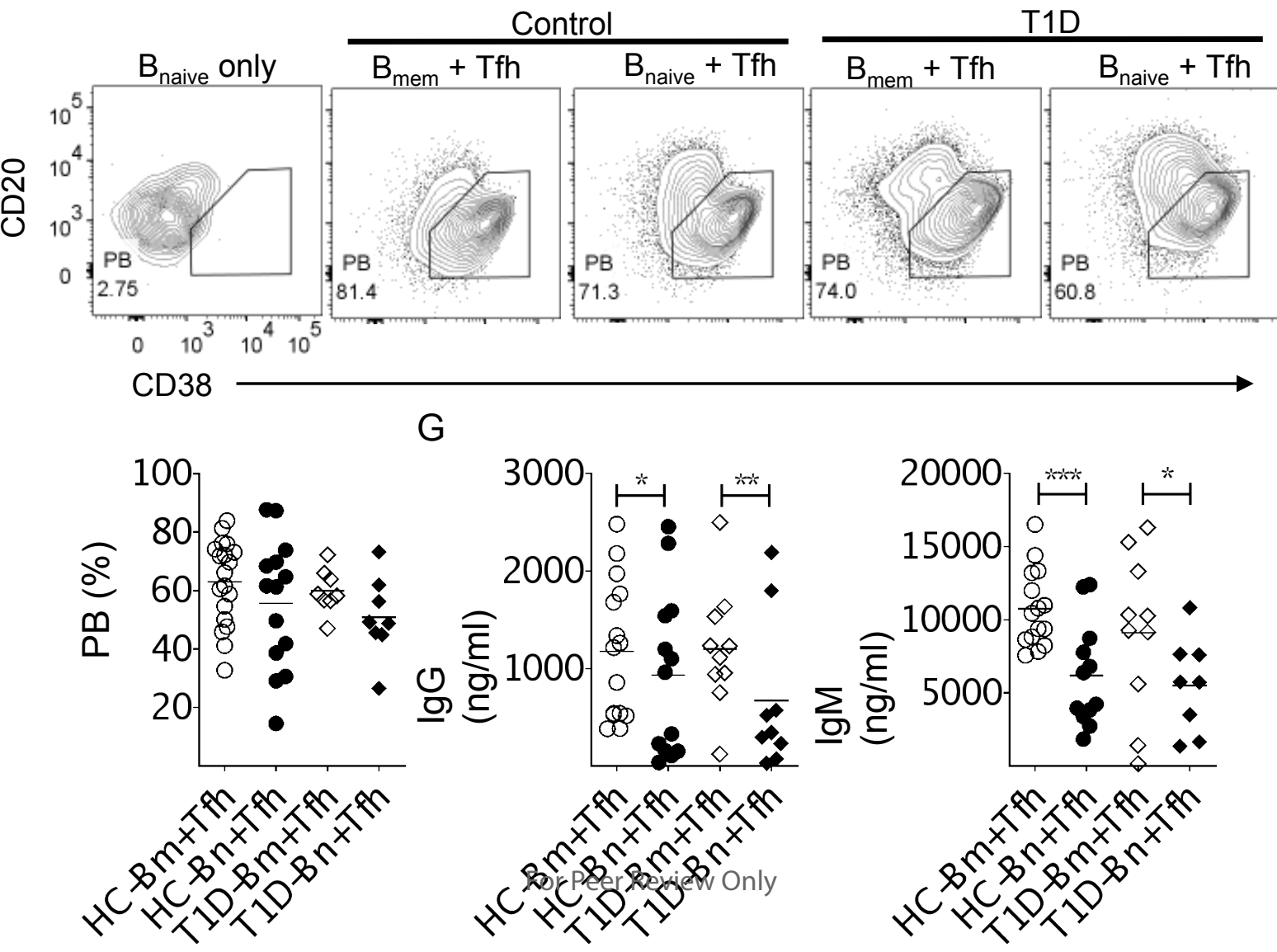
A

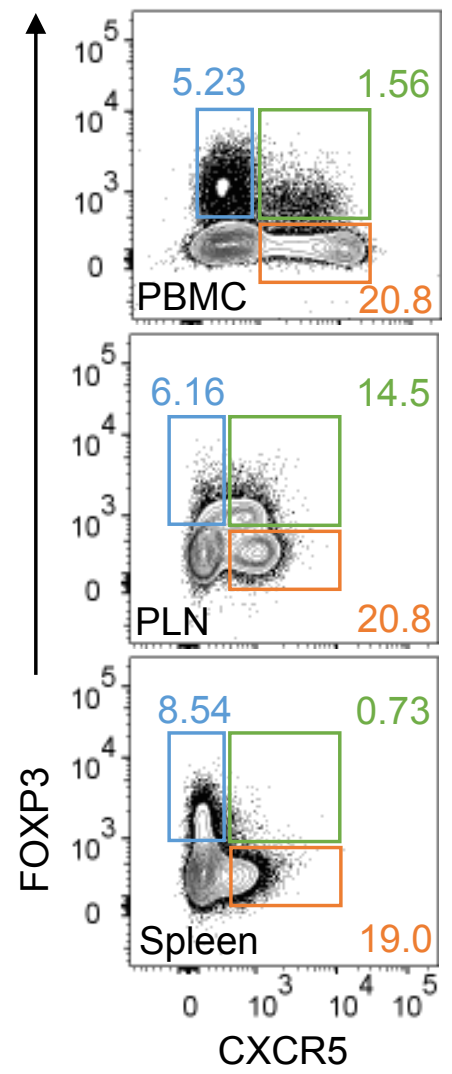

B
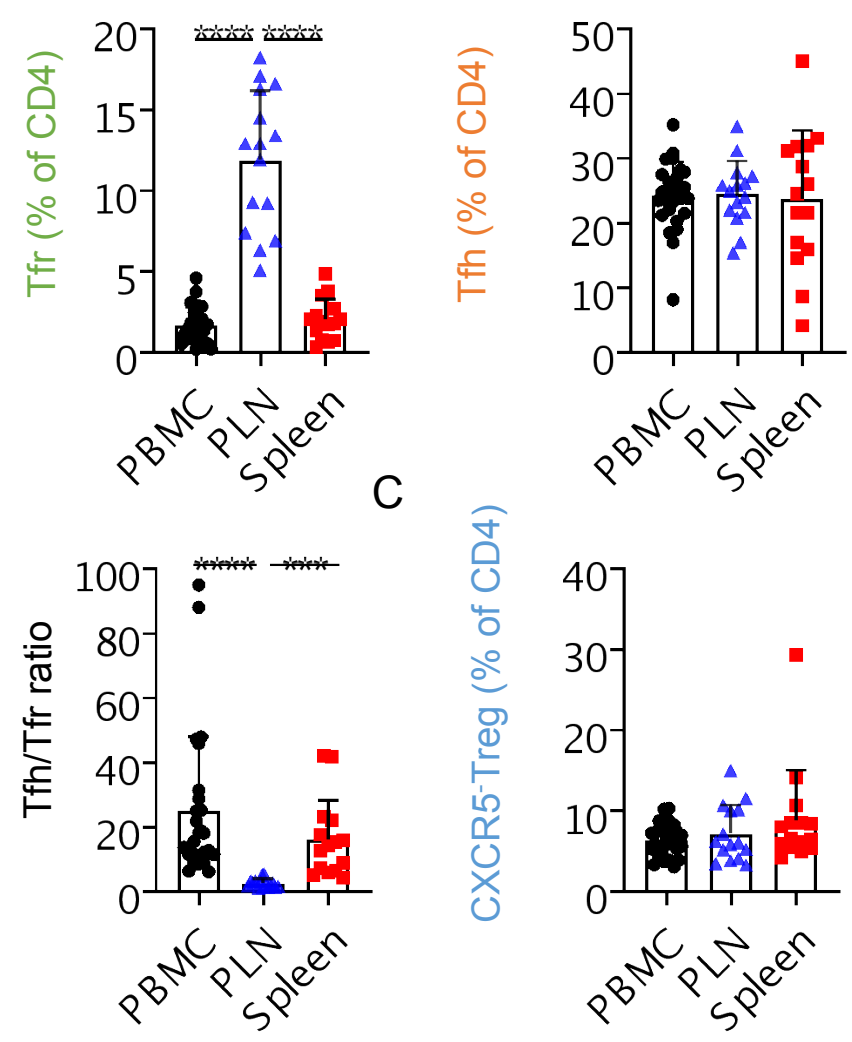

D

Gated on Tfr:
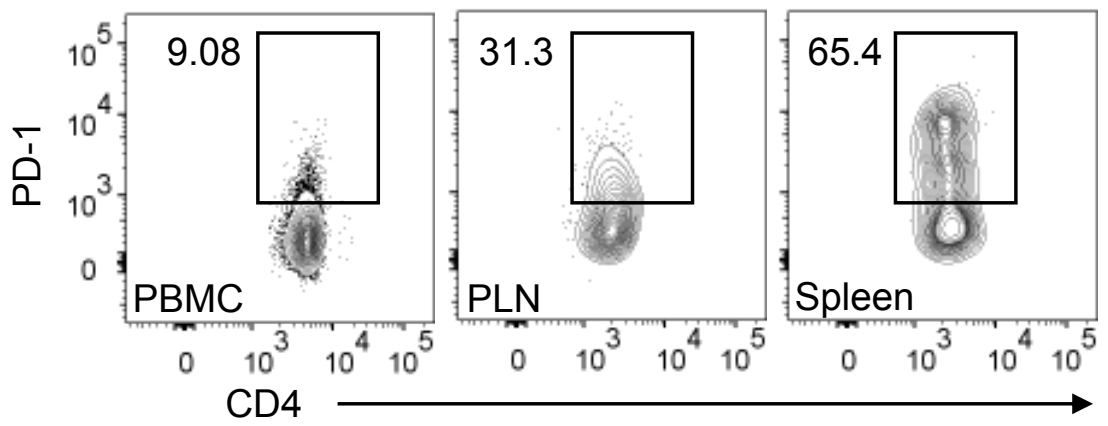

E

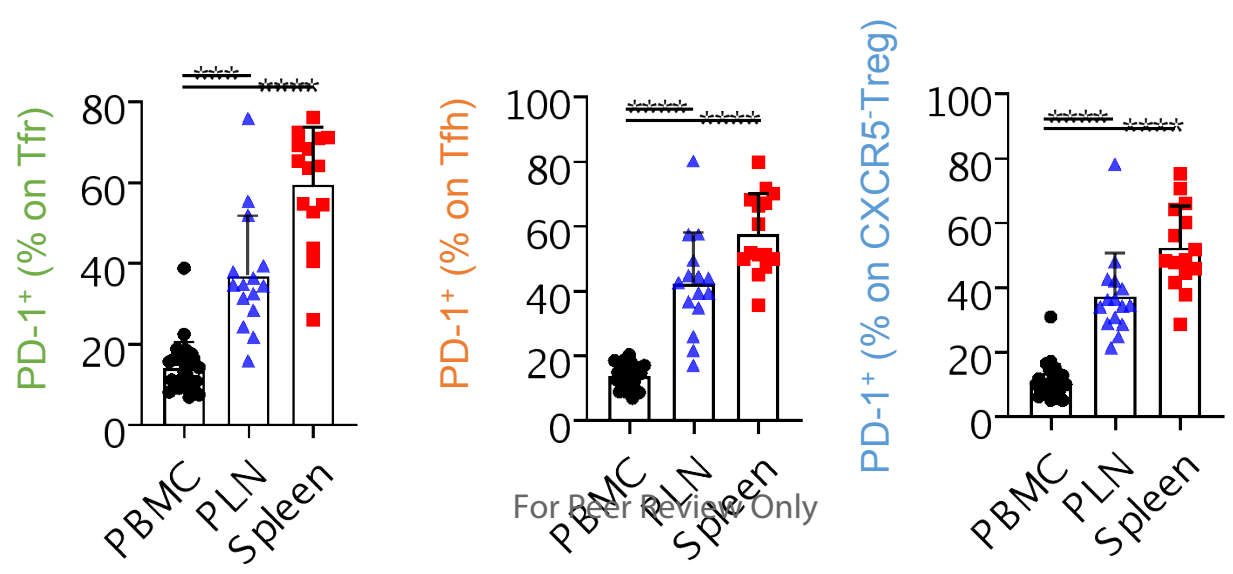


A

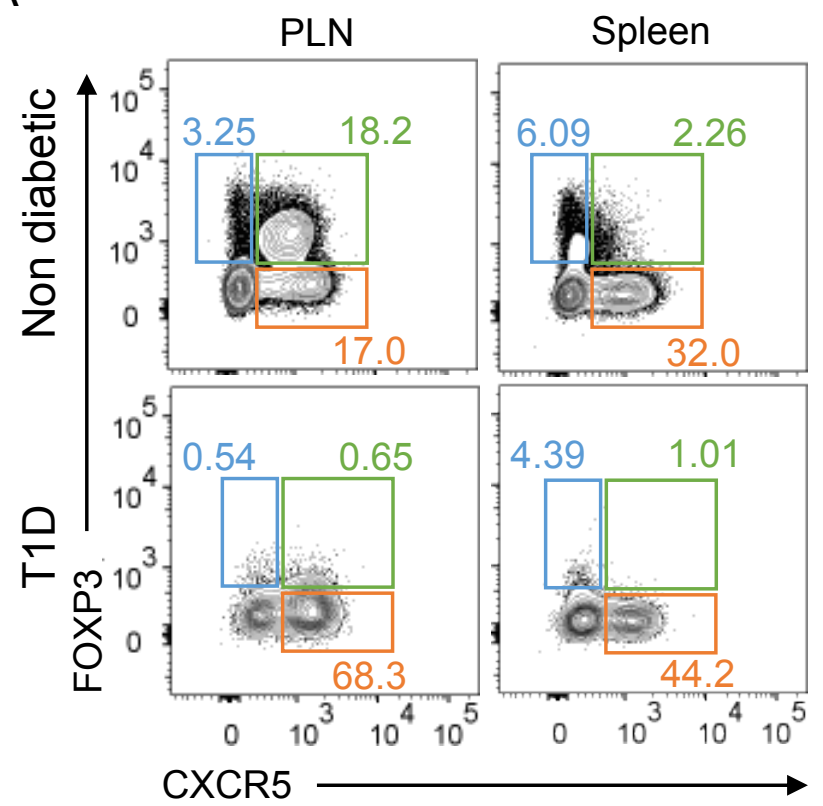

B PLN

Spleen
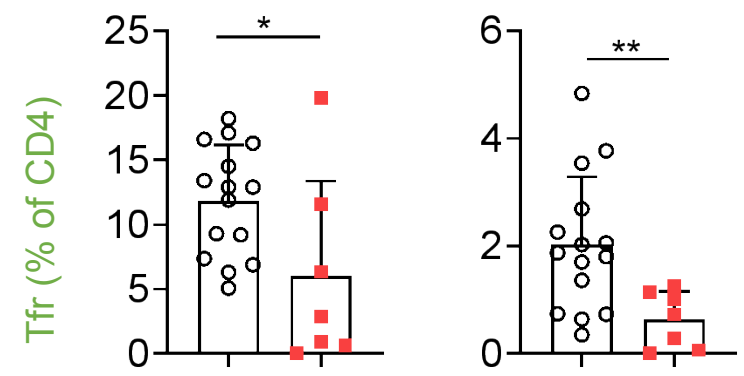

C

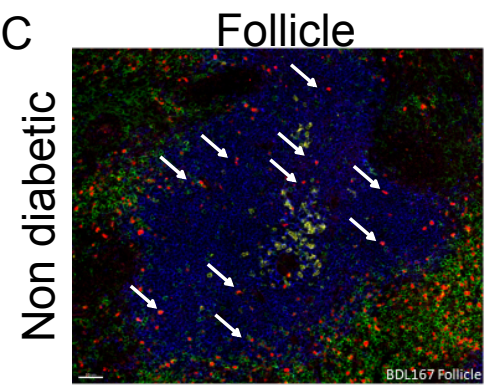

T cell zone
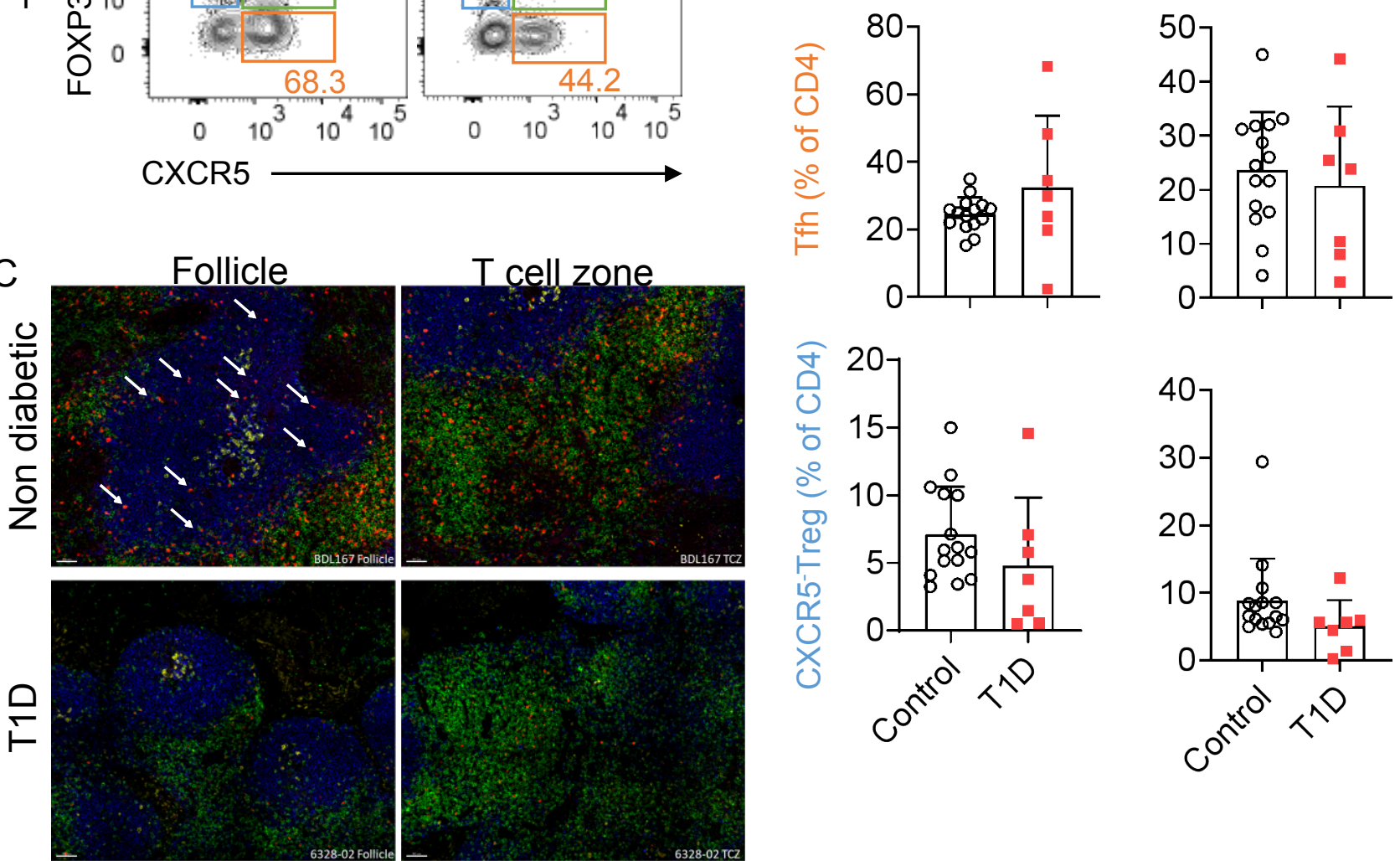

CD20 CD4 FOXP3 PD-1

D

Follicle
E FOXP3-

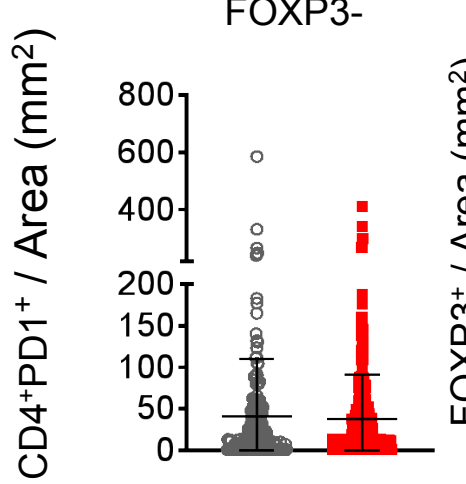

FOXP3+
T cell zone FOXP3-
- Control

- T1D

FOXP3+ 
B

A

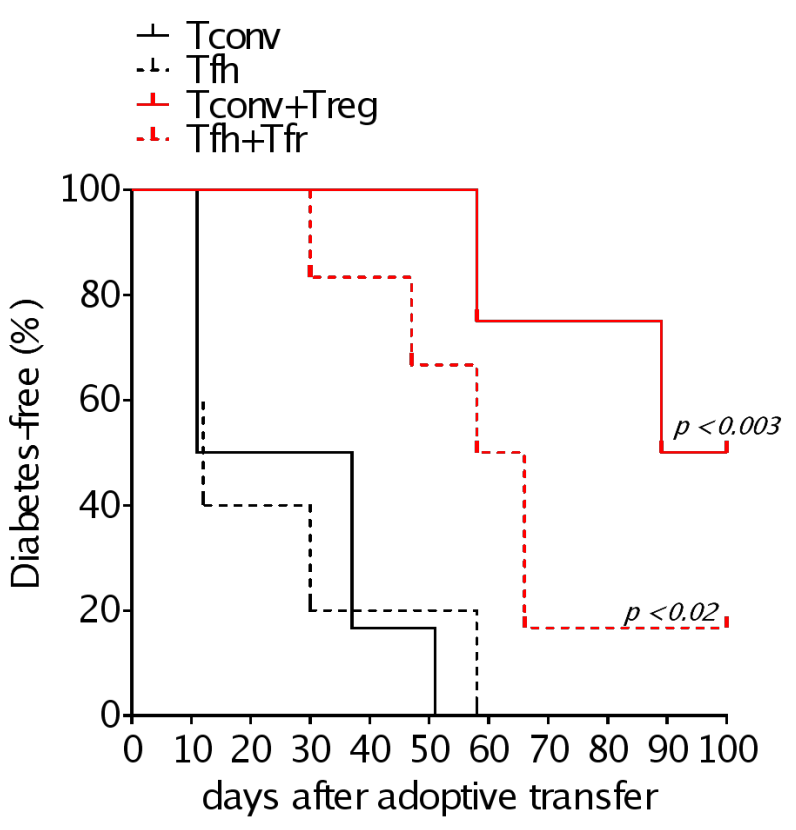

Tconv

เ. Tfh

- Tconv+Treg

Tconv +

Treg

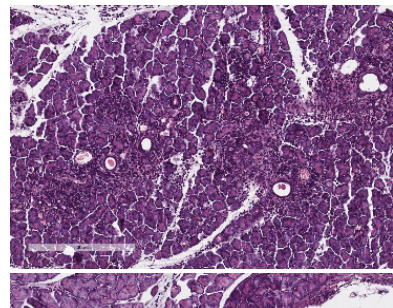

Tfh days after adoptive transfer

Tfh +

Tfr
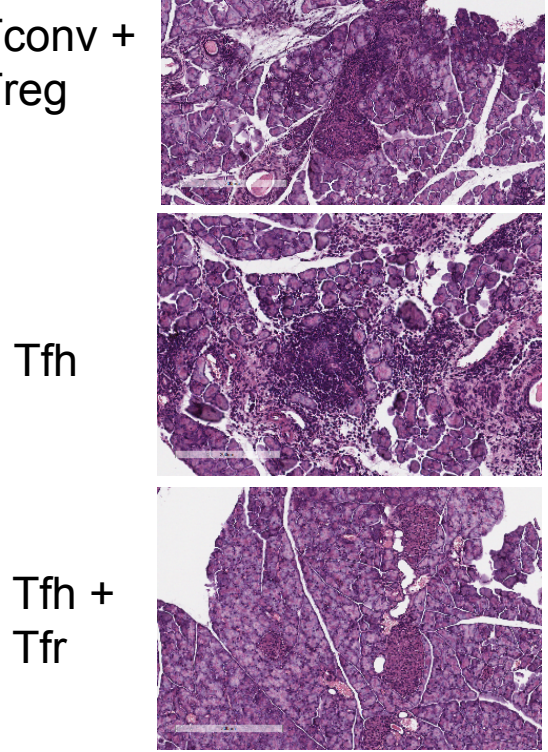
A
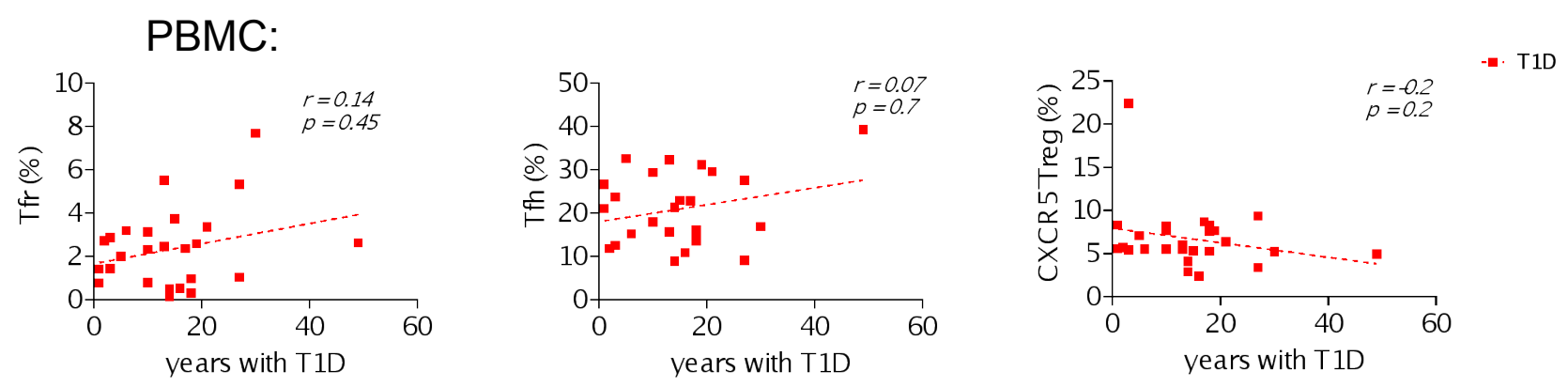

B
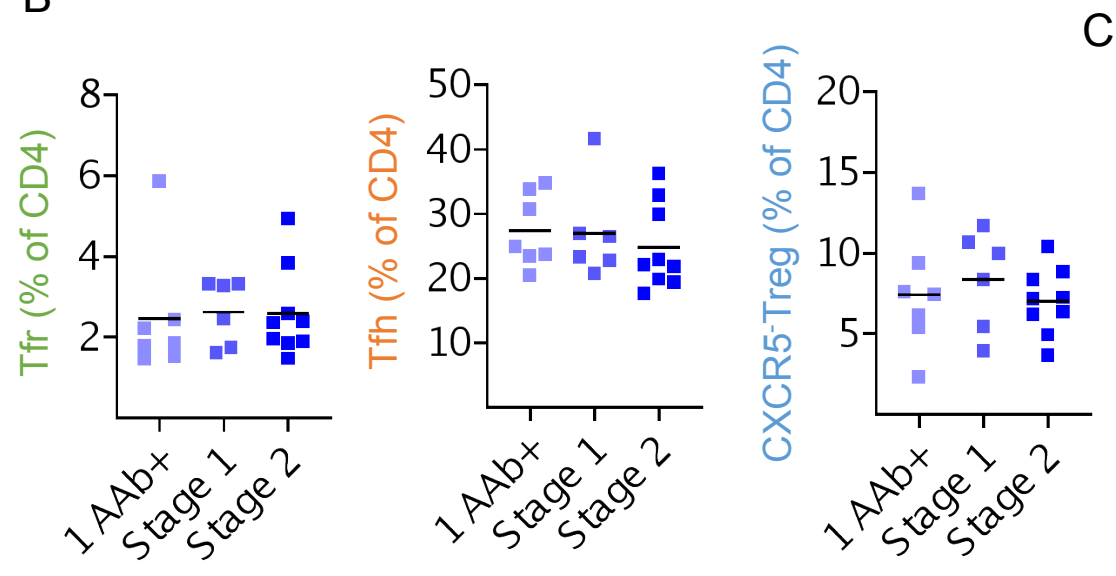

C
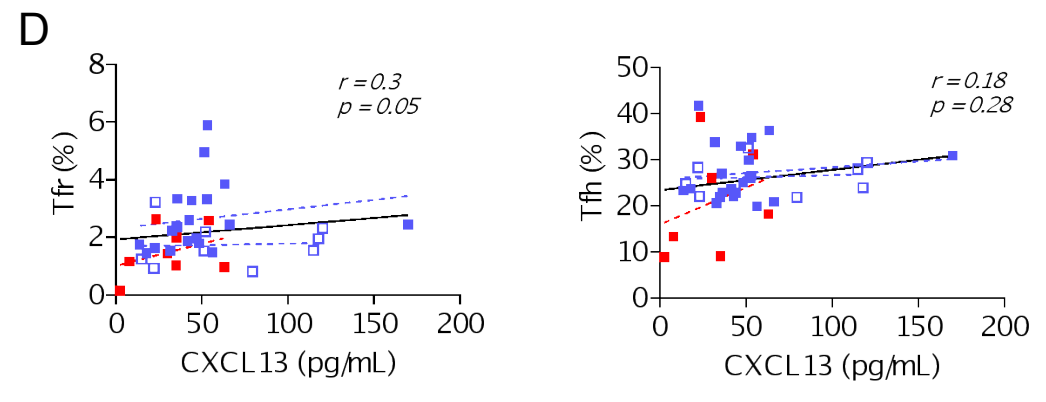
A

Whole Blood

B

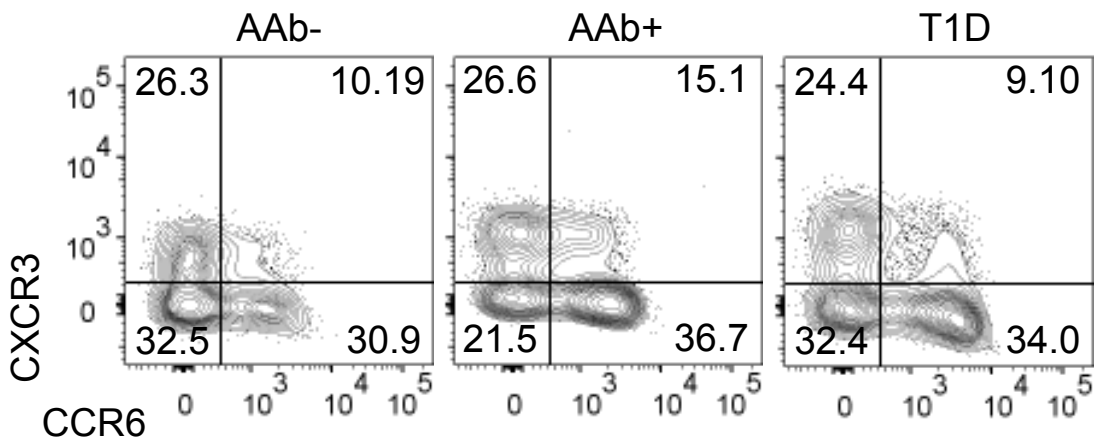

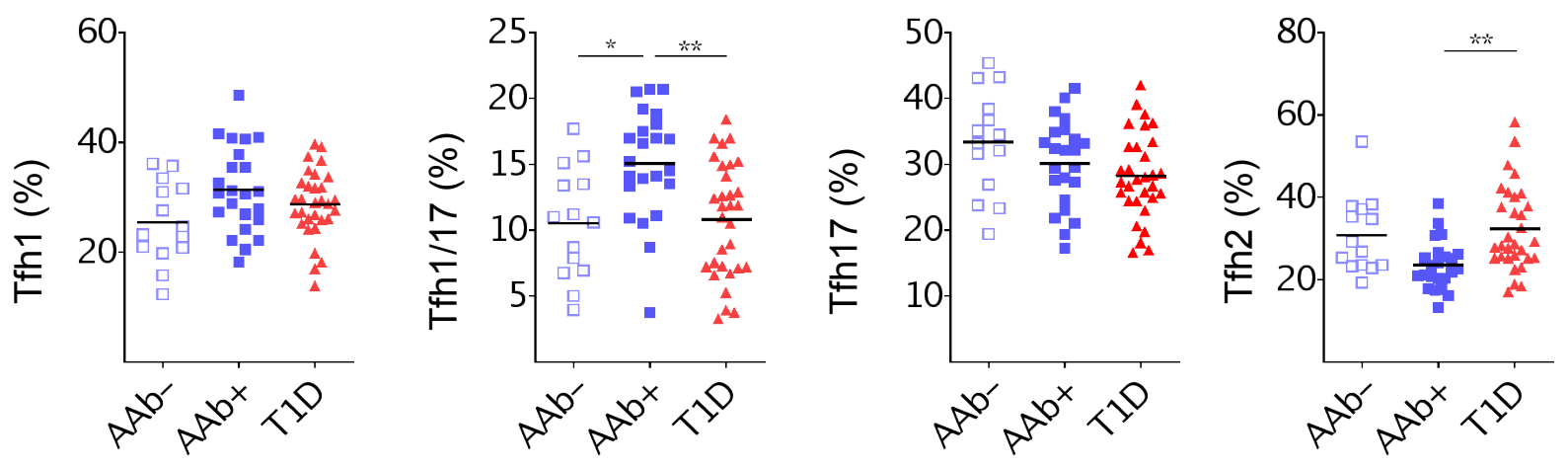

C

Whole Blood

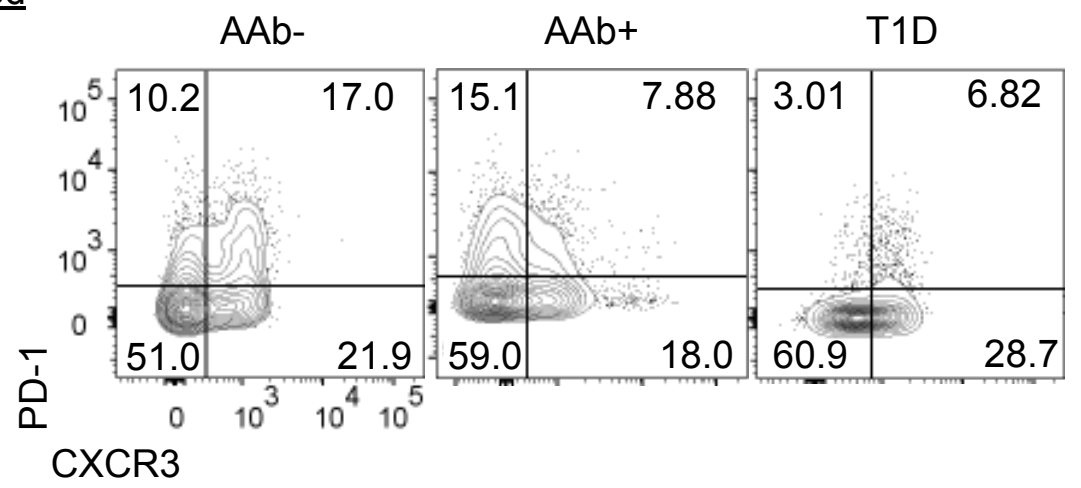

D

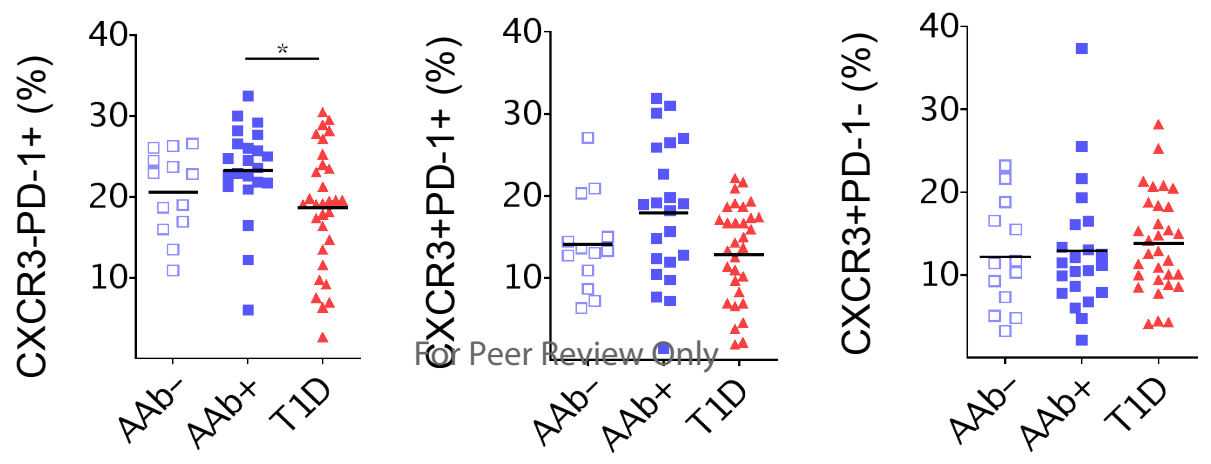


A

\section{Sorting strategy:}

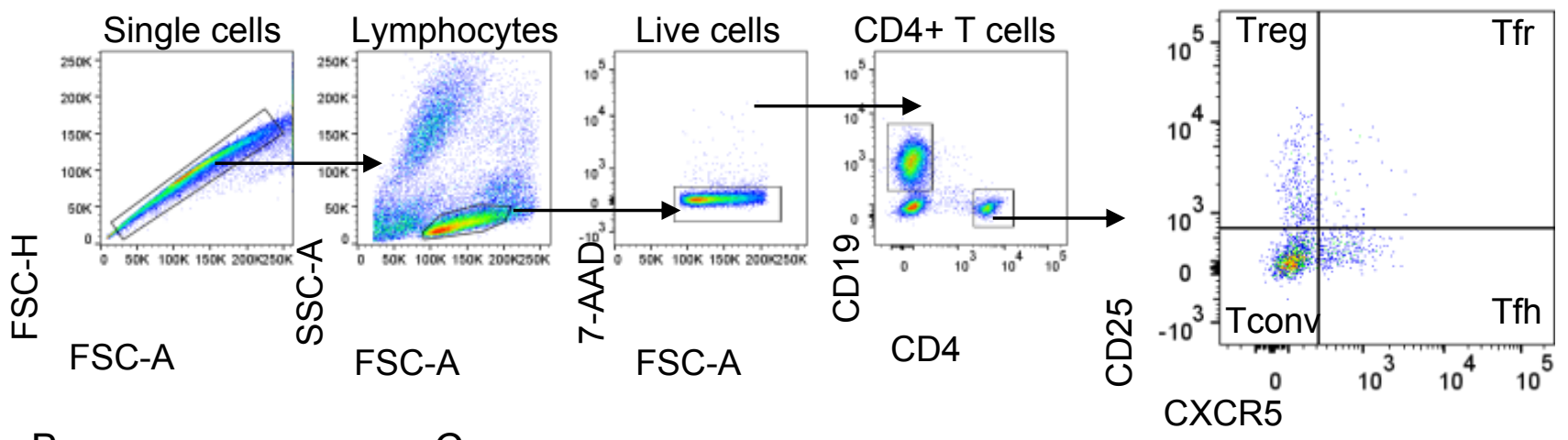

B

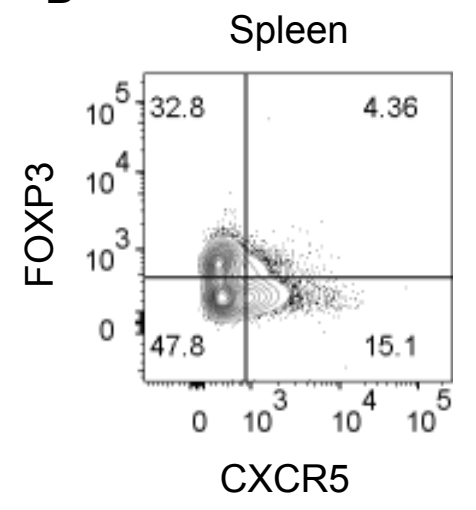

C

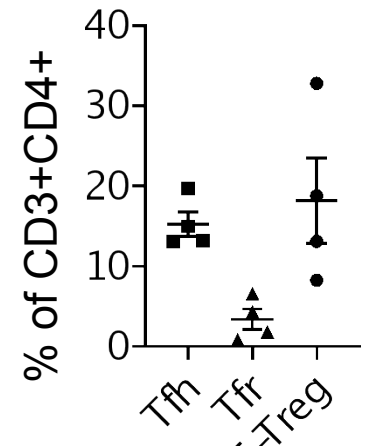

D

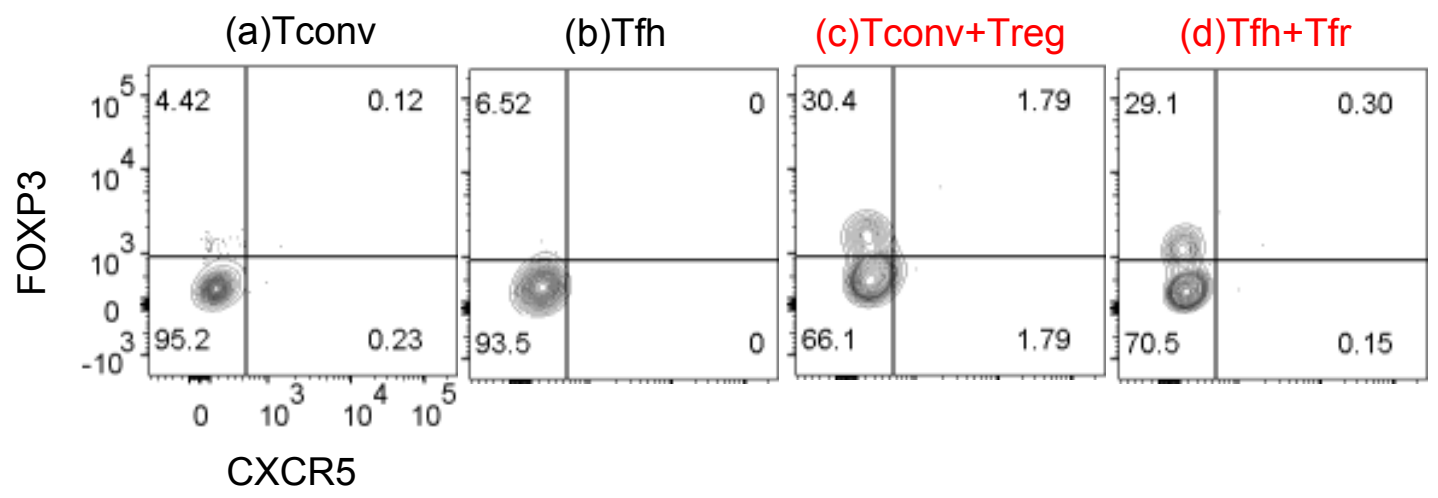

E

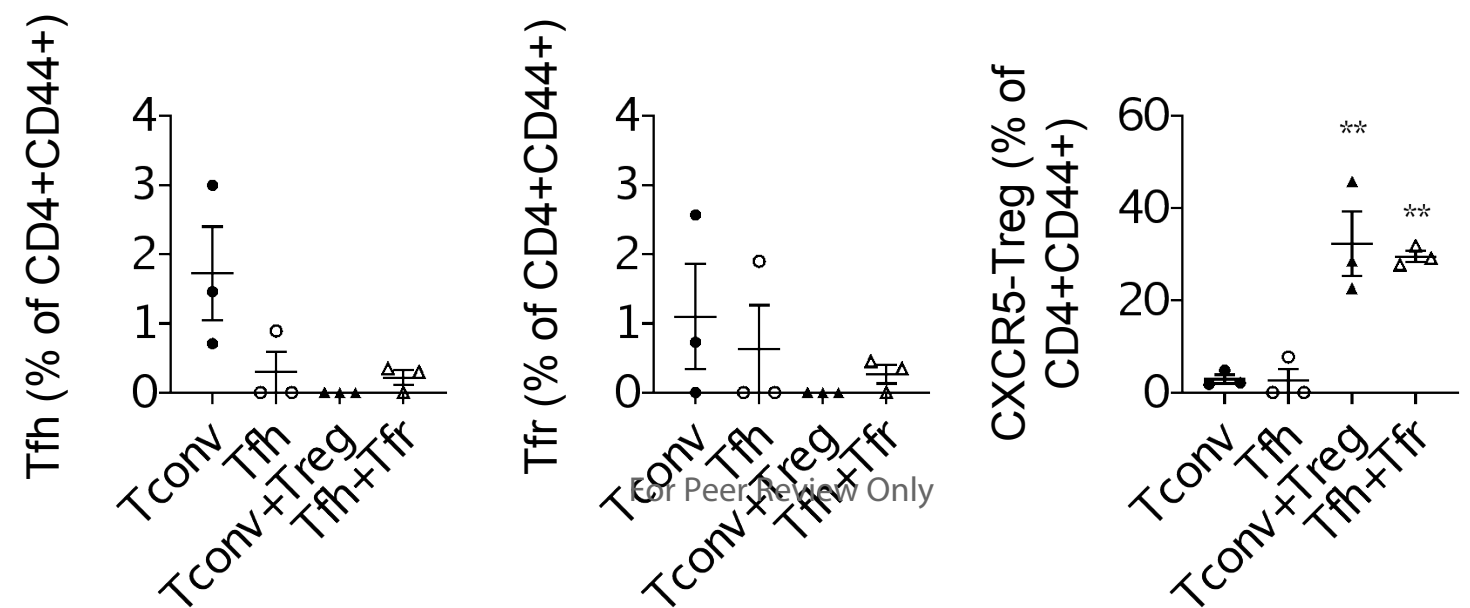


S upplementary Table 1

Characteristics of HC, T $1 \mathrm{D}$ and TrialNet blood donors

\begin{tabular}{|c|c|c|c|c|c|c|c|c|}
\hline \multicolumn{9}{|c|}{ Donor group and sample } \\
\hline & $\mathrm{HC}$ & $\mathrm{AAb}-$ & $1 \mathrm{AAb}+$ & Stage 1 & S tage 2 & RO T1D & LS T1D & \multirow{2}{*}{$P$ value } \\
\hline Characteristics & $n=52$ & $\mathrm{n}=14$ & $\mathrm{n}=10$ & $\mathrm{n}=8$ & $\mathrm{n}=9$ & $n=6$ & $\mathrm{n}=29$ & \\
\hline Median age, years (range) & $26(18-46)$ & $33(21-44)$ & $34(18-48)$ & $34(24-50)$ & $31(18-50)$ & $29(22-44)$ & $34(18-66)$ & 0.1 \\
\hline \# Men (\%) & $19(73,07)$ & 4 & $4(44,44)$ & $4(66,67)$ & $6(54,54)$ & $6(20,69)$ & 7 & \\
\hline Median age men, years (range) & $24(18-36)$ & $37(31-44)$ & $27(18-44)$ & $29(21-44)$ & $31(18-50)$ & $29(22-26)$ & $38(18-66)$ & 0.26 \\
\hline Type 1 diabetes duration (range) & NA & NA & NA & NA & NA & (28-107) days & $17(1-49)$ & \\
\hline
\end{tabular}


S upplementary Table 2

Page 35 of 41 Characteristics of TrialNet blood donors

Diabetes

\begin{tabular}{|c|c|c|c|c|c|c|}
\hline sample & $\begin{array}{l}\text { disease } \\
\text { duration }\end{array}$ & stage & age in yrs & $\operatorname{sex}$ & relatives $w / T 1 D$ & Aab (at diagnosis for T1D) \\
\hline preT1D007 & NA & $A A b-$ & 21 & $\mathrm{~F}$ & sister & NA \\
\hline preT $1 D 049$ & NA & AAb- & 21 & $\mathrm{~F}$ & uncle & NA \\
\hline preT1D680 & NA & $A A b-$ & 31 & $M$ & sister & NA \\
\hline preT1D685 & NA & $\mathrm{AAb}-$ & 24 & $\mathrm{~F}$ & father & NA \\
\hline preT1D703 & NA & $A A b-$ & 30 & $\mathrm{~F}$ & sister & NA \\
\hline preT1D706 & NA & $A A b-$ & 35 & $\mathrm{~F}$ & son & NA \\
\hline preT1D709 & NA & $A A b-$ & 37 & $\mathrm{~F}$ & son & NA \\
\hline preT1D710 & NA & AAb- & 43 & $\mathrm{~F}$ & father & NA \\
\hline preT1D712 & NA & $A A b-$ & 34 & $M$ & son & NA \\
\hline preT1D713 & NA & $A A b-$ & 35 & $\mathrm{~F}$ & son & NA \\
\hline preT1D1193 & NA & AAb- & 33 & $\mathrm{~F}$ & mother & NA \\
\hline preT1D1194 & NA & $A A b-$ & 44 & $M$ & father & NA \\
\hline preT1D1195 & NA & $A A b-$ & 40 & $M$ & father & NA \\
\hline preT1D1196 & NA & $A A b-$ & 38 & $\mathrm{~F}$ & mother & NA \\
\hline preT1D009 & NA & $1 \mathrm{AAb}+$ & 48 & $\mathrm{~F}$ & daughter & GAD65 \\
\hline preT1D052 & NA & $1 \mathrm{AAb}+$ & 48 & $\mathrm{~F}$ & daughter & GAD65 \\
\hline preT1D053 & NA & $1 \mathrm{AAb}+$ & 50 & $\mathrm{~F}$ & daughter & GAD65 \\
\hline preT1D229 & NA & $1 \mathrm{AAb}+$ & 42 & $\mathrm{~F}$ & brother & GAD65 \\
\hline preT1D330 & NA & $1 \mathrm{AAb}+$ & 22 & $\mathrm{~F}$ & mother & MIAA \\
\hline preT1D326 & NA & $1 \mathrm{AAb}+$ & 19 & $\mathrm{~F}$ & sister & GAD65 \\
\hline preT1D328 & NA & $1 \mathrm{AAb}+$ & 22 & $M$ & brother & MIAA \\
\hline preT1D541 & NA & $1 \mathrm{AAb}+$ & 34 & $\mathrm{~F}$ & son & GAD65 \\
\hline preT1D690 & NA & $1 \mathrm{AAb}+$ & 44 & $M$ & son & MIAA \\
\hline preT1D801 & NA & $1 \mathrm{AAb}+$ & 35 & $\mathrm{~F}$ & son & GAD65 \\
\hline preT1D022 & NA & Stage 1 & 20 & $\mathrm{~F}$ & mother & GAD65, ICA, ZNT8 \\
\hline preT1D023 & NA & Stage 1 & 22 & $M$ & brother & GAD65, ZNT8 \\
\hline preT1D046 & NA & Stage 1 & 34 & $M$ & mother and sister & GAD65, ZNT8 \\
\hline preT1D280 & NA & Stage 1 & 44 & $M$ & son & GAD65, ZNT8, MIAA \\
\hline preT1D315 & NA & Stage 1 & 23 & $\mathrm{~F}$ & father & GAD65, ZNT8 \\
\hline preT1D322 & NA & Stage 1 & 36 & $\mathrm{~F}$ & mother & GAD65, ICA \\
\hline preT1D590 & NA & Stage 1 & 21 & M & twin & GAD65, ICA, ZNT8 \\
\hline preT $1 D 697$ & NA & Stage 1 & 31 & $M$ & son & GAD65, ICA, ZNT8, MIAA \\
\hline preT1D008 & NA & Stage 2 & 41 & $M$ & sister & GAD65 \\
\hline preT1D022 & NA & Stage 2 & 21 & $\mathrm{~F}$ & mother & GAD65, ZNT8 \\
\hline preT1D046 & NA & Stage 2 & 34 & M & mother and sister & GAD65, ZNT8 \\
\hline preT $1 D 051$ & NA & Stage 2 & 49 & M & daughter & GAD65 \\
\hline preT1D052 & NA & Stage 2 & 47 & $\mathrm{~F}$ & daughter & GAD65 \\
\hline preT1D315 & NA & Stage 2 & 22 & $\mathrm{~F}$ & father & GAD65, ICA, ZNT8, MIAA \\
\hline preT1D321 & NA & Stage 2 & 22 & $M$ & brother and sister & GAD65 \\
\hline preT1D332 & NA & Stage 2 & 21 & $M$ & sister & GAD65, ICA, ZNT8 \\
\hline preT1D483 & NA & Stage 2 & 41 & $\mathrm{~F}$ & son and uncle & GAD65, ICA \\
\hline T1D341 & 49 days & RO & 51 & M & NA & GAD65, IA2, ZNT 8, MIAA \\
\hline T1D350 & 45 days & RO & 26 & $M$ & NA & GAD65, ZNT8 \\
\hline T1D351 & 107 days & RO & 44 & $\mathrm{~F}$ & NA & GAD65, IA2, ZNT 8, MIAA \\
\hline T1D353 & 72 days & RO & 23 & $M$ & NA & ZNT 8, ICA, GAD, IA2 \\
\hline T1D372 & 28 days & RO & 22 & M & NA & ZNT 8, IA2, IAA \\
\hline T1D472 & 1 year & RO & 23 & $\mathrm{~F}$ & sister & ZNT8, GAD65, IA2, ICA \\
\hline T1D339 & 1 years & LT & 33 & $M$ & NA & NA \\
\hline $\mathrm{T} 1 \mathrm{D} 340$ & 2 years & LT & 50 & $\mathrm{~F}$ & NA & GAD65, IA2, ZNT 8, MIAA \\
\hline T1D344 & 10 years & LT & 28 & $\mathrm{~F}$ & NA & MIAA \\
\hline T1D345 & 13 years & LT & 56 & $M$ & NA & MIAA \\
\hline T1D349 & 14 years & LT & 38 & $\mathrm{~F}$ & NA & NA \\
\hline T1D352 & 10 years & LT & 27 & $\mathrm{~F}$ & NA & NA \\
\hline T1D354 & 1 year & LT & 25 & $\mathrm{~F}$ & NA & GAD65, IA2, ZNT 8, MIAA \\
\hline T1D356 & 3 years & LT & 38 & $\mathrm{~F}$ & NA & GAD65, IA2, MIAA \\
\hline T1D357 & 5 years & LT & 42 & $\mathrm{~F}$ & NA & MIAA \\
\hline $\mathrm{T} 1 \mathrm{D} 358$ & 18 years & LT & 37 & $\mathrm{~F}$ & NA & GAD65, IA2, ZNT 8 \\
\hline T1D363 & 18 years & LT & 27 & $\mathrm{~F}$ & NA & IA2, MIAA \\
\hline T1D364 & 17 years & LT & 25 & $M$ & NA & IAA \\
\hline T1D365 & 3 years & LT & 20 & $\mathrm{~F}$ & NA & GAD65 \\
\hline T1D397 & 14 years & LT & 27 & $\mathrm{~F}$ & NA & IAA \\
\hline T1D398 & 27 years & LT & 33 & M & NA & IAA \\
\hline T1D399 & 18 years & LT & 29 & $\mathrm{~F}$ & NA & IAA \\
\hline T1D400 & 19 years & LT & 33 & $\mathrm{~F}$ & NA & NA \\
\hline $\mathrm{T} 1 \mathrm{D} 401$ & 49 years & LT & 66 & $M$ & NA & IAA \\
\hline T1D403 & 5 years & LT & 63 & $\mathrm{~F}$ & NA & ICA, GAD65 \\
\hline T1D404 & 47 years & LT & 38 & M & NA & ND \\
\hline T1D469 & 21 years & LT & 22 & $\mathrm{~F}$ & NA & ICA, GAD65 \\
\hline T1D470 & ND & LT & ND & ND & NA & GAD65, IA2 \\
\hline T1D471 & 16 years & LT & 25 & $\mathrm{~F}$ & sister & GAD65, IA2, MIAA, ICA \\
\hline $\mathrm{T} 1 \mathrm{D} 473$ & 15 years & LT & 24 & $\mathrm{~F}$ & mother & ICA, GAD65, IA2 \\
\hline T1D474 & 30 years & & NA & NA \\
\hline T1D495 & 13 years & \multicolumn{3}{|c|}{ réter Revięv OnFy } & sister & NA \\
\hline T1D496 & 27 years & LT & 28 & $\mathrm{~F}$ & sister & NA \\
\hline $\mathrm{T} 1 \mathrm{D} 497$ & 6 years & LT & 18 & $M$ & sister & GAD65, ICA \\
\hline T1D498 & 10 years & LT & 22 & $\mathrm{~F}$ & brother & GAD65, IA2, ZNT 8, MIAA \\
\hline
\end{tabular}


Supplementary Table 3

Characteristics of T1D and nondiabetic donors, PBMC, spleen and PLN

$$
\text { Donor group and sample }
$$

\begin{tabular}{|c|c|c|c|c|c|c|c|}
\hline & $\mathrm{HC}$ PBMC & diabetic sp & on diabetic PLN & T1D PBMC & T1D spleen & T1D PLN & $P$ value \\
\hline Characteristics & $\mathrm{n}=23$ & $\mathrm{n}=15$ & $\mathrm{n}=15$ & $\mathrm{n}=35$ & $\mathrm{n}=7$ & $\mathrm{n}=7$ & \\
\hline Median age, years (range) & $26(18-46)$ & $56(39-64)$ & $56(39-64)$ & $32(18-66)$ & $30(20-57)$ & $30(20-57$ & $<0.0001$ \\
\hline \# Men (\%) & $19(73,07)$ & $11(19,64)$ & $11(73,33)$ & 13 & $6(20)$ & $6(20)$ & \\
\hline Median age men, years (range) & $24(18-36)$ & $57(39-64)$ & $57(39-64)$ & $33(18-66)$ & $30(20-57)$ & $30(20-57$ & $<0.0001$ \\
\hline Type 1 diabetes duration, years (range) & NA & NA & NA & RO+LS & $16(1-38)$ & $16(1-38)$ & \\
\hline
\end{tabular}




\section{Page 37 of 41}

Diabetes

S upplementary Table 4

$\mathrm{nPOD}$ and HSR spleen and PLN cases used in flow cytometry

\begin{tabular}{|c|c|c|c|c|c|c|c|}
\hline Source & Case \# & Sex & Age & $\mathrm{BMI}$ & HLA & Years with T1D & Ethnicity \\
\hline \multirow{9}{*}{$\mathrm{nPOD}$} & 6322 & $M$ & 22 & 23.6 & ND & 17 & CAUCASIAN \\
\hline & 6325 & $\mathrm{~F}$ & 20 & 31.2 & DR 4/DR 15 and DQ6 & 6 & $\mathrm{AA}$ \\
\hline & 6328 & $\mathrm{M}$ & 39 & 24 & ND & 20 & $\mathrm{H} / \mathrm{L}$ \\
\hline & 6330 & $\mathrm{M}$ & 22 & 22.6 & ND & 18 & CAUCASIAN \\
\hline & 6367 & $M$ & 24 & 25.7 & DR 4/DR 7 & 2 & CAUCASIAN \\
\hline & 6414 & $\mathrm{M}$ & 23.1 & 28.4 & DR 4/DR 11 & 0.4 & $\mathrm{AA}$ \\
\hline & 6418 & $\mathrm{M}$ & 24.9 & 26.4 & ND & 11 & CAUCASIAN \\
\hline & 6419 & $M$ & 57 & 27.5 & ND & 38 & CAUCASIAN \\
\hline & 6422 & $\mathrm{M}$ & 22.8 & 25.1 & ND & 21 & CAUCASIAN \\
\hline \multirow{15}{*}{ HSR } & BD141 & $\mathrm{F}$ & 59 & 59 & DR 1/DR 12 & $\mathrm{NA}$ & CAUCASIAN \\
\hline & BD142 & $\mathrm{M}$ & 60 & 25.9 & DR 11/DR 15 & $\mathrm{NA}$ & CAUCASIAN \\
\hline & BD143 & $\mathrm{M}$ & 50 & 22.7 & DR 7/DR 13 & $\mathrm{NA}$ & CAUCASIAN \\
\hline & BD144 & $\mathrm{F}$ & 52 & 25.6 & DR 4/DR 13 & $\mathrm{NA}$ & CAUCASIAN \\
\hline & BD145 & $\mathrm{F}$ & 52 & 20.5 & DR 3/DR 11 & $\mathrm{NA}$ & CAUCASIAN \\
\hline & BD146 & $\mathrm{M}$ & 39 & 27 & DR 1/DR 14 & $\mathrm{NA}$ & CAUCAS IAN \\
\hline & BD147 & $\mathrm{M}$ & 62 & 21.8 & DR 7/DR 11 & $\mathrm{NA}$ & CAUCASIAN \\
\hline & BD148 & $\mathrm{M}$ & 64 & 27.5 & DR 7/DR 11 & $\mathrm{NA}$ & CAUCASIAN \\
\hline & BD149 & $\mathrm{M}$ & 62 & 25.7 & DR 8/DR 11 & $\mathrm{NA}$ & CAUCASIAN \\
\hline & BD150 & $\mathrm{F}$ & 52 & 31.2 & DR 3/DR 4 & $\mathrm{NA}$ & CAUCAS IAN \\
\hline & BD151 & $\mathrm{M}$ & 52 & 29.1 & ND & $\mathrm{NA}$ & CAUCASIAN \\
\hline & BD152 & $M$ & 52 & 24.4 & DR 7/DR 14 & $\mathrm{NA}$ & CAUCASIAN \\
\hline & BD153 & $\mathrm{M}$ & 63 & 25.9 & DR 11/DR 14 & $\mathrm{NA}$ & CAUCASIAN \\
\hline & BD154 & $\mathrm{M}$ & 61 & 27.8 & DR 7/DR 14 & $\mathrm{NA}$ & CAUCASIAN \\
\hline & BD155 & $M$ & 62 & 27.8 & DR 7/DR 11 & $\mathrm{NA}$ & CAUCASIAN \\
\hline
\end{tabular}


Supplementary Table 5

nPOD and HSR PLN cases used in immunofluorescence microscopy

\begin{tabular}{|c|c|c|c|c|c|}
\hline Source & Case \# & Sex & Age & Years with T1D & Ethnicity \\
\hline \multirow{8}{*}{$\mathrm{nPOD}$} & $6138-02$ & $\mathrm{~F}$ & 49.2 & 41 & CAUCASIAN \\
\hline & $6240-02$ & $F$ & 58 & 22 & CAUCASIAN \\
\hline & $6246-02$ & $\mathrm{~F}$ & 41 & 27 & $A A$ \\
\hline & $6325-02$ & $\mathrm{~F}$ & 20 & 6 & AA \\
\hline & $6328-01$ & $M$ & 39 & 20 & $\mathrm{H} / \mathrm{L}$ \\
\hline & $6330-02$ & $M$ & 22 & 18 & CAUCASIAN \\
\hline & 6418-02 & $M$ & 24.9 & 11 & CAUCASIAN \\
\hline & $6422-02$ & $M$ & 22.8 & 21 & CAUCASIAN \\
\hline \multirow{8}{*}{ HSR } & BDL 162 & $\mathrm{~F}$ & 28 & NA & CAUCASIAN \\
\hline & BDL 167 & $F$ & 54 & NA & CAUCASIAN \\
\hline & BDL 172 & $\bar{M}$ & 47 & NA & CAUCASIAN \\
\hline & BDL 173 & $F$ & 49 & NA & CAUCASIAN \\
\hline & BDL 176 & $\mathrm{M}$ & 42 & $\mathrm{NA}$ & CAUCASIAN \\
\hline & BDL 178 & $\mathrm{~F}$ & 50 & $\mathrm{NA}$ & CAUCASIAN \\
\hline & BDL 179 & $F$ & 26 & NA & CAUCASIAN \\
\hline & BDL 196 & $\mathrm{M}$ & 60 & $\mathrm{NA}$ & CAUCASIAN \\
\hline
\end{tabular}




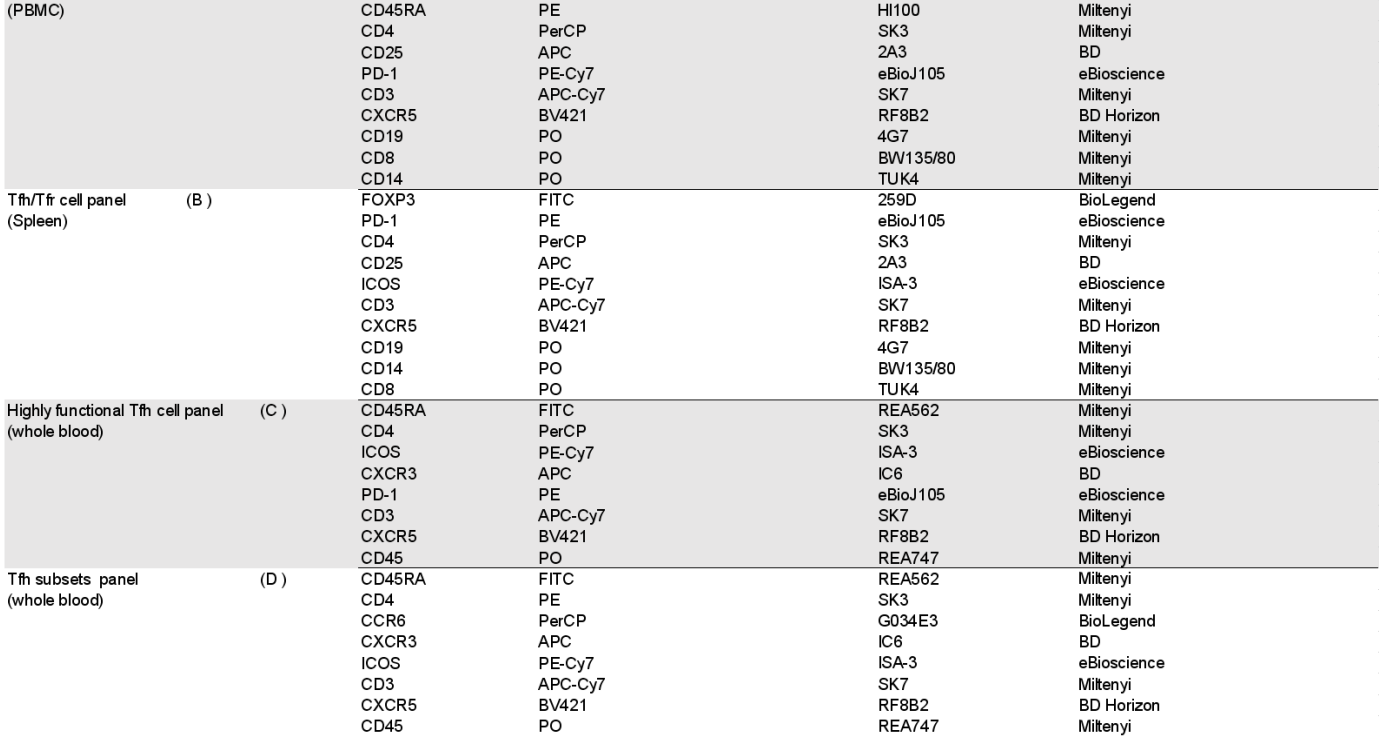


Supplementary Table 7

Antbodies and immunostaining panel used for immunofluorescence

\begin{tabular}{|c|c|c|c|c|}
\hline \multirow{9}{*}{$\begin{array}{l}\text { Immunofluorescence panel } \\
\text { Tfh/Tf cell panel } \\
\text { (PLN) }\end{array}$} & Antibody & Fluorochrome & Clone & Manufacturer \\
\hline & PD1 & & EPR4877 & Abcam \\
\hline & Donkey $\times$ Rabbit & BV421 & & Biolegend \\
\hline & LAG3 & & polyclonal Goat $\lg G$ & $R \& D$ \\
\hline & Donkey $x$ Goat & $A \times 546$ & & Life Technologies \\
\hline & CD20 & EF615 & & eBio \\
\hline & $\mathrm{CD} 4$ & $A \times 488$ & polyclonal Goat IgG & $R \& D$ \\
\hline & K167 & BV510 & & Biolegend \\
\hline & FOXP3 & A $\times 647$ & & Biolegend \\
\hline
\end{tabular}




\section{SUPPLEMENTARY ONLINE REPOSITORY}

SUPPLEMENTARY FIGURE 1. Blood Tfh and Tfr cells in human T1D. (A) The nonparametric (Spearman) two-tailed test was used for correlation analyses between percentage of Tfh, Tfr, CXCR5- Treg cells and years with T1D in living subjects with symptomatic T1D. (B) Percentage of Tfr $\left(\mathrm{CXCR}^{+} \mathrm{FOXP3}^{+}\right)$, CXCR5-Treg $\left(\mathrm{CXCR}^{-} \mathrm{FOXP}^{+}\right)$, and Tfh $\left(\mathrm{CXCR}^{+} \mathrm{FOXP}^{-}\right)$cells in single $\mathrm{AAb}^{+}(n=7)$, stage $1(n=6)$ and stage $2(n=9)$. (C) Graph shows Tfr $\left(\mathrm{CXCR}^{+} \mathrm{FOXP}^{+}\right)$, cells in other (non-DR3 or DR4 HLA) $(n=6), \mathrm{DR} 3 / \mathrm{DRX}(n=9)$, $\operatorname{DR} 4 / \mathrm{DRX}(n=4)$ and DR3/DR4 $(n=4)$. (D) The non-parametric (Spearman) two-tailed test was used for correlation analyses between percentage of Tfh, Tfr, CXCR5- Treg cells and Tfh/Tfr ratio with plasma CXCL13 concentration.

SUPPLEMENTARY FIGURE 2. Distribution of Tfh subsets in patients with presymptomatic and symptomatic T1D. (A) Representative flow cytometry plots (B) and graph for Tfh2 (CXCR3-CCR6), Tfh17 (CXCR3-CCR6 $\left.{ }^{+}\right), \quad$ Tfh1/17 (CXCR3 $\left.{ }^{+} \mathrm{CCR}^{+}\right)$and Tfh1 $\left(\mathrm{CXCR}^{+}{ }^{+} \mathrm{CCR} 6{ }^{-}\right)$, gated on singlets, lymphocytes, $\mathrm{CD} 3^{+} \mathrm{CD} 19^{-}$and $\mathrm{CD}^{+}, \mathrm{CD}^{+} \mathrm{CXCR}^{+}$cells. (C) Representative flow cytometry plots for CXCR3-PD-1 ${ }^{+}$Tfh cells, gated on singlets, lymphocytes, $\mathrm{CD}^{+} \mathrm{CD}^{+}, \mathrm{CD}^{+} \mathrm{CXCR}^{+}$cells. (D) Percentage of CXCR3- PD- $1^{+}$Tfh cells from patients with presymptomatic and symptomatic T1D. Tfh cell subsets in $\mathrm{AAb}^{-}(n=14), \mathrm{AAb}^{+}(n$ $=23)$ and T1D $(n=31)$. In all graphs, each point represents an individual donor with the median indicated by a black line. Asterisks indicate statistical significance as calculated by KruskalWallis. ${ }^{*} \mathrm{p}<0.05 * * \mathrm{p}<0.005$

\section{SUPPLEMENTARY FIGURE 3. Expression of CD25 and functional properties of tissue-} resident CXCR5 $^{+} \mathrm{FOXP3}^{+}$Tfr cells. (A) gating strategy for sorting $\mathrm{Tfh}\left(\mathrm{CXCR}^{+} \mathrm{CD} 25^{-}\right)$, $\mathrm{Tfr}$ $\left(\mathrm{CXCR}^{+} \mathrm{CD} 25^{+}\right)$, Tconv (CXCR5-CD25-) and Treg $\left(\mathrm{CXCR} 5^{-} \mathrm{CD} 25^{+}\right)$cells sorted from spleen of BDC2.5 mice. (B) Representative gating and (C) frequencies of Tfh (CXCR5 $\left.{ }^{+} \mathrm{FOXP} 3^{-}\right)$, Tfr $\left(\mathrm{CXCR}^{+} \mathrm{FOXP}^{+}\right)$and $\mathrm{CXCR} 5^{-}$Treg cells $\left(\mathrm{CXCR}^{-}{ }^{-\mathrm{FOXP}} 3^{+}\right)$from spleen and BDC2.5 mice $(\mathrm{n}=$ 4). (D) Representative gating and (E) frequencies of Tfh, Tfr and CXCR5- Treg cells from peripheral blood of adoptively transferred mice at day 12 post injection. In all graphs, points 
represent individual mice. Asterisks indicate statistical significance as calculated by paired-t test. $* * \mathrm{p}<0.01$. 